\title{
A possible pathway for rapid growth of sulfate during haze days in China
}

\author{
Guohui Li ${ }^{1}$, Naifang Bei ${ }^{2}$, Junji Cao ${ }^{1}$, Rujin Huang ${ }^{1}$, Jiarui Wu ${ }^{1}$, Tian Feng ${ }^{1,2}$, Yichen Wang ${ }^{1}$, Suixin Liu ${ }^{1}$, \\ Qiang Zhang ${ }^{3}$, Xuexi Tie ${ }^{1}$, and Luisa T. Molina ${ }^{4,5}$ \\ ${ }^{1}$ Key Lab of Aerosol Chemistry and Physics, SKLLQG, Institute of Earth Environment, Chinese Academy of Sciences, \\ Xi'an, China \\ ${ }^{2}$ School of Human Settlements and Civil Engineering, Xi'an Jiaotong University, Xi' an, Shaanxi, China \\ ${ }^{3}$ Department of Earth System Science, Tsinghua University, Beijing, China \\ ${ }^{4}$ Molina Center for Energy and the Environment, La Jolla, CA, USA \\ ${ }^{5}$ Massachusetts Institute of Technology, Cambridge, MA, USA
}

Correspondence to: Guohui Li (ligh@ieecas.cn), Junji Cao (jjcao@ieecas.cn), and Rujin Huang (rujin.huang@psi.ch)

Received: 9 November 2016 - Discussion started: 14 November 2016

Revised: 21 February 2017 - Accepted: 22 February 2017 - Published: 7 March 2017

\begin{abstract}
Rapid industrialization and urbanization have caused frequent occurrence of haze in China during wintertime in recent years. The sulfate aerosol is one of the most important components of fine particles $\left(\mathrm{PM}_{2.5}\right)$ in the atmosphere, contributing significantly to the haze formation. However, the heterogeneous formation mechanism of sulfate remains poorly characterized. The relationships of the observed sulfate with $\mathrm{PM}_{2.5}$, iron, and relative humidity in Xi'an, China have been employed to evaluate the mechanism and to develop a parameterization of the sulfate heterogeneous formation involving aerosol water for incorporation into atmospheric chemical transport models. Model simulations with the proposed parameterization can successfully reproduce the observed sulfate rapid growth and diurnal variations in Xi' an and Beijing, China. Reasonable representation of sulfate heterogeneous formation in chemical transport models considerably improves the $\mathrm{PM}_{2.5}$ simulations, providing the underlying basis for better understanding the haze formation and supporting the design and implementation of emission control strategies.
\end{abstract}

\section{Introduction}

Sulfate is a main component of aerosols or fine particles $\left(\mathrm{PM}_{2.5}\right)$ in the atmosphere and plays a key role in global climate change. The direct and indirect radiative effects in- duced by sulfate aerosols have constituted one of the major uncertainties in current assessments of climate change (IPCC, 2013). In addition, deposition of sulfate aerosols exerts deleterious impacts on ecosystems through acidification of soils, lakes, and marshes (e.g., Schindler, 1988; Gerhardsson et al., 1994). Sulfate is also an important contributor to the haze formation and substantially reduces the atmospheric visibility during hazy days (e.g., He et al., 2014; Guo et al., 2014).

The main source of sulfate in the atmosphere is the oxidation of sulfur dioxide $\left(\mathrm{SO}_{2}\right)$, which is directly emitted from fossil fuel combustion, industrial processes, and volcanoes, or generated by oxidation of other sulfur-containing species, such as dimethyl sulfide (DMS). The conversion of $\mathrm{SO}_{2}$ to sulfate involves various processes, including gas-phase oxidations by hydroxyl radicals $(\mathrm{OH})$ and stabilized criegee intermediates (sCI) (Mauldin III et al., 2012), aqueous reactions in cloud or fog droplets, and heterogeneous reactions associated with aerosols (Seinfeld and Pandis, 2006).

Model studies have been performed to investigate the formation of sulfate aerosols on global or regional scales (Barrie et al., 2001). Previous global model results, considering the contribution of $\mathrm{SO}_{2}$ gas-phase oxidation and aqueous reactions in cloud or fog droplets driven by ozone $\left(\mathrm{O}_{3}\right)$ and hydrogen peroxide $\left(\mathrm{H}_{2} \mathrm{O}_{2}\right)$, have suggested that $\mathrm{SO}_{2}$ mixing ratios are generally overestimated while sulfate concentrations tend to be underestimated, indicating that the two $\mathrm{SO}_{2}$ 
oxidation pathways still cannot close the gap between field observations and modeling studies (Kasibhatla et al., 1997; Laskin et al., 2003). Incorporation of aqueous $\mathrm{SO}_{2}$ oxidation by oxygen catalyzed by transition metal ions in models has improved sulfate simulations compared to measurements (Jacob and Hoffmann, 1983; Jacob et al., 1984, 1989; Pandis et al., 1992; Alexander et al., 2009), and recent studies have further shown the enhanced role of transition metal ion catalysis during in-cloud oxidation of $\mathrm{SO}_{2}$ (Harris et al., 2013). However, models still underestimate $\mathrm{SO}_{2}$ oxidation in winter source regions due to lack of cloud or fog or a missing oxidation mechanism (Feichter et al., 1996; Kasibhatla et al., 1997; Barrie et al., 2001). Therefore, heterogeneous conversion of $\mathrm{SO}_{2}$ to sulfate associated with aerosols provides a possible pathway for improving the sulfate simulations in chemical transport models (CTMs) (Kasibhatla et al., 1997; Zhang et al., 2015).

Many experimental studies have been conducted to investigate the heterogeneous reactions of $\mathrm{SO}_{2}$ on various oxides and mineral dust, but the underlying sulfate formation mechanism is still not comprehensively understood. Generally, the complicated sulfate heterogeneous formation from $\mathrm{SO}_{2}$ is parameterized as a first-order irreversible uptake by aerosols in CTMs, with a reactive uptake coefficient ranging from $10^{-4}$ to 0.1 and also heavily depending on relative humidity in the atmosphere (Wang et al., 2014). It is still imperative to develop a ubiquitous parameterization of the $\mathrm{SO}_{2}$ heterogeneous reaction to reasonably represent sulfate formation in CTMs.

In recent years, China has frequently experienced severe and persistent haze pollution caused by elevated $\mathrm{PM}_{2.5}$ concentrations, and field measurements have shown that sulfate aerosols are one of the most important species in $\mathrm{PM}_{2.5}(\mathrm{He}$ et al., 2014; Tian et al., 2016). Reasonable representation of sulfate aerosols provides an underlying basis for $\mathrm{PM}_{2.5}$ simulations. Laboratory experiments, field measurements, and model simulations have significantly advanced our understanding of $\mathrm{SO}_{2}$ heterogeneous reactions in the atmosphere, providing a good opportunity to develop a parameterization to more reasonably represent the sulfate formation in CTMs. In this study, a parameterization for sulfate formation from $\mathrm{SO}_{2}$ heterogeneous reactions has been developed based on the daily filter measurements in Xi' an since 2003, and verified using the Weather Research and Forecast model with Chemistry (WRF-CHEM) in Xi' an and Beijing, China.

\section{Model and methodology}

\subsection{WRF-CHEM model}

In the present study, a specific version of the WRF-CHEM model (Grell et al., 2005) is utilized to assess the proposed heterogeneous sulfate parameterization, which is developed by Li et al. (2010, 2011a, b, 2012) at the Molina Center for Energy and the Environment. A new flexible gas-phase chemical module is incorporated into the model to consider different chemical mechanisms, and the CMAQ/Models3 aerosol module developed by US EPA is adopted for aerosol simulations. Surface dry depositions of chemical species are parameterized following Wesely (1989), and the wet deposition is calculated using the method in the CMAQ. The photolysis rates are calculated using the fast radiative transfer model (FTUV) in which the aerosol and cloud effects on photolysis are included (Li et al., 2005, 2011a).

The ISORROPIA Version 1.7 (Nenes et al., 1998) is used to predict inorganic aerosols in the WRF-CHEM model. A nontraditional SOA module is employed to calculate secondary organic aerosol (SOA) formation, including the volatility basis set (VBS) modeling method in which primary organic components are assumed to be semivolatile and photochemically reactive and are distributed in logarithmically spaced volatility bins. The SOA contributions from glyoxal and methylglyoxal are also considered to be first-order irreversible uptake by aerosol particles and cloud droplets in the model. Detailed information can be found in $\mathrm{Li}$ et al. (2011b).

Two persistent heavy haze pollution episodes are selected in the present study: (1) 16 to 27 December 2013 in the Guanzhong basin (GZB); and (2) 13 to 21 January 2014 in Beijing-Tianjin-Hebei (BTH) (Fig. 1). Detailed model configurations and aerosol species observation sites are given in Table 1. A very severe haze episode occurred in GZB during the period from 16 to 27 December 2013, with an average $\mathrm{PM}_{2.5}$ concentration of $325.6 \mu \mathrm{g} \mathrm{m}^{-3}$. The maximum of the average $\mathrm{PM}_{2.5}$ concentration in GZB even exceeded $500 \mathrm{~g} \mathrm{~m} \mathrm{~m}^{-3}$ during the episode. The average temperature and relative humidity in $\mathrm{Xi}$ 'an were $3.7^{\circ}$ and $72 \%$ during the episode, respectively, and the average wind speed was around $3.7 \mathrm{~m} \mathrm{~s}^{-1}$. The average $\mathrm{PM}_{2.5}$ concentration from 13 to 21 January $2014 \mathrm{in} \mathrm{BTH}$ was $195.3 \mu \mathrm{g} \mathrm{m}^{-3}$, with a maximum of $363.9 \mu \mathrm{g} \mathrm{m}^{-3}$. The average temperature and relative humidity in Beijing during the episode was $-0.5^{\circ}$ and $42 \%$, respectively, and the average wind speed was about $7.4 \mathrm{~m} \mathrm{~s}^{-1}$.

\subsection{Statistical methods for comparisons}

The mean bias (MB) and the index of agreement (IOA) are used to evaluate the performance of the WRF-CHEM model in simulating gas-phase species and aerosols against measurements. The IOA varies from 0 to 1 , with 1 indicating perfect agreement of the prediction with the observation.

$$
\mathrm{MB}=\frac{1}{N} \sum_{i=1}^{N}\left(P_{i}-O_{i}\right)
$$


Table 1. WRF-CHEM model configurations and observation sites.

\begin{tabular}{lll}
\hline Regions & Guanzhong Basin (GZB) & Beijing-Tianjin-Hebei (BTH) \\
\hline Simulation period & 16 to 27 December 2013 & 13 to 21 January 2014 \\
Domain size & $150 \times 150$ & \\
Domain center & $34.25^{\circ} \mathrm{N}, 109^{\circ} \mathrm{E}$ & $39^{\circ} \mathrm{N}, 117^{\circ} \mathrm{E}$ \\
Horizontal resolution & $6 \mathrm{~km} \times 6 \mathrm{~km}$ & \\
Vertical resolution & $35 \mathrm{vertical}$ levels with a stretched vertical grid with spacing ranging \\
& from $30 \mathrm{~m}$ near the surface, to 500 $\mathrm{m}$ at 2.5 and $1 \mathrm{~km}$ above $14 \mathrm{~km}$ \\
Microphysics scheme & WSM 6-class graupel scheme (Hong and Lim, 2006) \\
Boundary layer scheme & MYJ TKE scheme (Janjić, 2002) \\
Surface layer scheme & MYJ surface scheme (Janjić, 2002) \\
Land-surface scheme & Unified Noah land-surface model (Chen and Dudhia, 2001) \\
Longwave radiation scheme & Goddard longwave scheme (Chou and Suarez, 2001) \\
Shortwave radiation scheme & Goddard shortwave scheme (Chou and Suarez, 1999) \\
Meteorological boundary and initial conditions & NCEP $1^{\circ} \times 1^{\circ}$ reanalysis data \\
Chemical initial and boundary conditions & MOZART 6h output (Horowitz et al., 2003) \\
Anthropogenic emission inventory & Developed by Zhang et al. (2009) and Li et al. (2017) \\
Biogenic emission inventory & MEGAN model developed by Guenther et al. (2006) \\
Aerosol observation sites & & \\
City & Xi'an & Beijing \\
Longitude and latitude & $34.23^{\circ} \mathrm{N}, 108.88^{\circ} \mathrm{E}$ & $40.00^{\circ} \mathrm{N}, 116.38^{\circ} \mathrm{E}$ \\
\hline
\end{tabular}

$\mathrm{IOA}=1-\frac{\sum_{i=1}^{N}\left(P_{i}-O_{i}\right)^{2}}{\sum_{i=1}^{N}\left(\left|P_{i}-\bar{O}\right|+\left|O_{i}-\bar{O}\right|\right)^{2}}$,

where $P_{i}$ and $O_{i}$ are the calculated and observed pollutant concentrations, respectively. $N$ is the total number of the predictions used for comparisons, and $\bar{P}$ and $\bar{O}$ represent the averages of the prediction and observation, respectively.

\subsection{Pollutant measurements}

The hourly near-surface $\mathrm{NO}_{2}, \mathrm{SO}_{2}$, and $\mathrm{PM}_{2.5}$ mass concentrations in GZB and BTH are released by China's Ministry of Environmental Protection (China MEP) and can be downloaded from the website http://www.aqistudy.cn/. The daily filter measurements of aerosol species have been taken since 2003 at the Institute of Earth Environment, Chinese Academy of Sciences (hereafter referred to as IEECAS, $34.23^{\circ} \mathrm{N}, 108.88^{\circ} \mathrm{E}$ ) in Xi'an, China (Fig. 1a). The sulfate, nitrate, ammonium, and organic aerosols are measured by the Aerodyne High Resolution Time-of-Flight Aerosol Mass Spectrometer (HR-ToF-AMS) with a novel $\mathrm{PM}_{2.5}$ lens from 13 December 2013 to 6 January 2014 at the IEECAS site in Xi' an and from 9 to 26 January 2014 at the Institute of Remote Sensing and Digital Earth, Chinese Academy of Sciences $\left(40.00^{\circ} \mathrm{N}, 116.38^{\circ} \mathrm{E}\right)$ in Beijing (Fig. 1b). Detailed information about the HR-ToF-AMS measurement can be found in Elser et al. (2016).

\section{Results and discussions}

\subsection{Parameterization of $\mathrm{SO}_{2}$ heterogeneous reaction involving aerosol water}

Figure 2 shows the scatter plot of the wintertime sulfate and $\mathrm{PM}_{2.5}$ daily mass concentrations at IEECAS from 2003 to 2010. Wintertime is defined as December of one year to February of the next year. The observed daily $\mathrm{PM}_{2.5}$ mass concentrations frequently exceed $150 \mathrm{\mu g} \mathrm{m}^{-3}$ during wintertime, showing that Xi'an has experienced heavy air pollution. The sulfate aerosols constitute about $15.7 \%$ of the $\mathrm{PM}_{2.5}$ mass concentration on average, and the occurrence frequency with the daily sulfate mass concentration exceeding $50 \mu \mathrm{g} \mathrm{m}^{-3}$ is around $25.7 \%$.

The observed high level of sulfate aerosols is hardly interpreted using $\mathrm{SO}_{2}$ gas-phase oxidations by $\mathrm{OH}$ and sCI due to the low $\mathrm{O}_{3}$ level in the winter. The insolation is weak during wintertime in northern China, and unfavorable for photochemical activities. The $\mathrm{O}_{3}$ formation is slow and the observed $\mathrm{O}_{3}$ concentrations are very low, particularly during haze episodes. The real-time hourly measurements of $\mathrm{O}_{3}$ and $\mathrm{PM}_{2.5}$ concentrations during the winters of 2013 and 2015 are analyzed as follows in GZB (5 cities, 39 sites, Fig. 1a), which have been released by China MEP since 2013. Values of the hourly $\mathrm{PM}_{2.5}$ concentrations $\left(\left[\mathrm{PM}_{2.5}\right]\right)$ are first subdivided into 20 bins with the interval of $25 \mu \mathrm{g} \mathrm{m}^{-3} . \mathrm{O}_{3}$ concentrations $\left(\left[\mathrm{O}_{3}\right]\right)$ in the five cities as $\left[\mathrm{PM}_{2.5}\right]$ are assembled, and an average of $\left[\mathrm{O}_{3}\right]$ in each bin are calculated (Nakajima et al., 2001; Kawamoto et al., 2006). As shown in Fig. 3, when $\left[\mathrm{PM}_{2.5}\right]$ increase from 10 to $75 \mu \mathrm{g} \mathrm{m}^{-3},\left[\mathrm{O}_{3}\right]$ significantly decrease from around 41 to $23 \mu \mathrm{g} \mathrm{m}^{-3}$; when $\left[\mathrm{PM}_{2.5}\right]$ exceed 

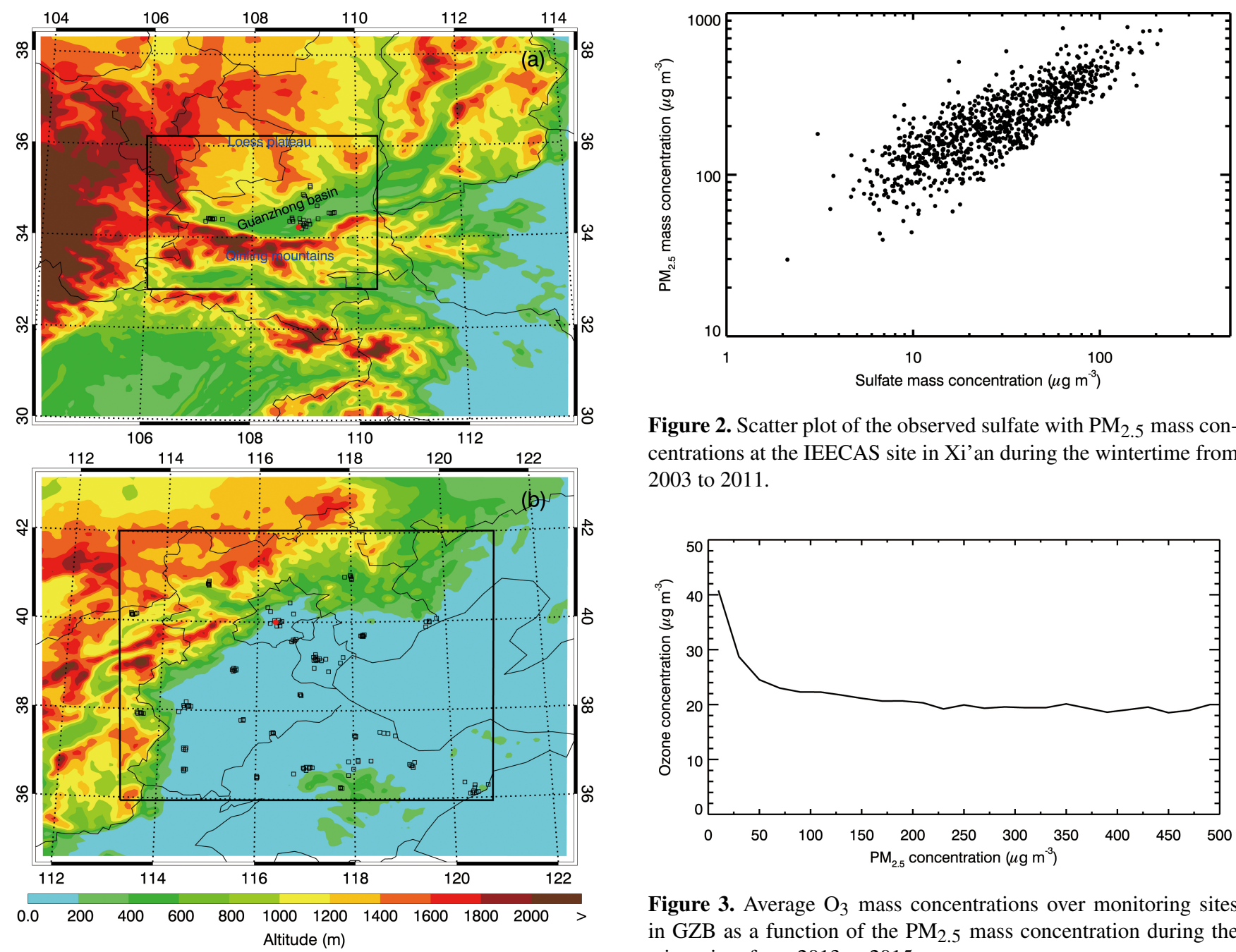

Figure 2. Scatter plot of the observed sulfate with $\mathrm{PM}_{2.5}$ mass concentrations at the IEECAS site in Xi' an during the wintertime from 2003 to 2011.

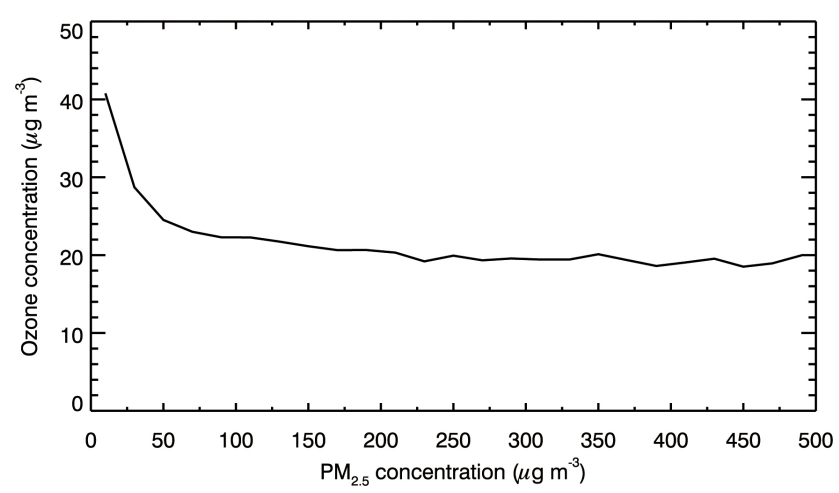

Figure 3. Average $\mathrm{O}_{3}$ mass concentrations over monitoring sites in GZB as a function of the $\mathrm{PM}_{2.5}$ mass concentration during the wintertime from 2013 to 2015.

Figure 1. WRF-CHEM simulation domains with topography for (a) the Guanzhong basin and (b) Beijing-Tianjin-Hebei. The black squares represent ambient monitoring sites. The red filled circles in (a) and (b) denote the deployment locations of the HR-ToF-AMS in Xi' an and Beijing.

$200 \mu \mathrm{g} \mathrm{m}^{-3},\left[\mathrm{O}_{3}\right]$ fluctuate between 18 and $21 \mu \mathrm{g} \mathrm{m}^{-3}$. The average $\left[\mathrm{O}_{3}\right]$ in the five cities during the winters of 2013 and 2015 are $27 \mathrm{\mu g} \mathrm{m}^{-3}$ (about $13.5 \mathrm{ppbv}$ ). Considering the determining role of $\mathrm{O}_{3}$ in the formation of $\mathrm{OH}$ and $\mathrm{sCI}$ in the atmosphere, the very low level of $\left[\mathrm{O}_{3}\right]$ during wintertime significantly reduces the efficiency of the sulfate formation from $\mathrm{SO}_{2}$ oxidation by $\mathrm{OH}$ and $\mathrm{sCI}$.

Humid conditions have been observed to facilitate the sulfate formation in the atmosphere (e.g., Sun et al., 2013; Zheng et al., 2015). Figure 4 presents the scatter plot of the wintertime sulfate at IEECAS and the relative humidity (RH) at an adjacent meteorological station from 2003 to 2010 . The observed sulfate displays a positive correlation with the $\mathrm{RH}$ with the correlation coefficient of 0.70 , indicating that the aerosol water induced by the aerosol wet growth might play

an important role in the sulfate formation. It is worthy to note that, since high RH often coincides with stagnation, the concentrations of a lot of pollutants also build up during high RH periods. There are two possible pathways for the sulfate formation: bulk aqueous-phase oxidation of $\mathrm{SO}_{2}$ in aerosol water and heterogeneous reaction of $\mathrm{SO}_{2}$ on aerosol surfaces involving aerosol water.

The heterogeneous reaction of $\mathrm{SO}_{2}$ on dust surfaces has been investigated comprehensively, but the sulfate formation mechanism is still not completely understood. Possible mechanisms have been proposed, such as that mineral dust and $\mathrm{NO}_{2}$ enhance the conversion of $\mathrm{SO}_{2}$ to sulfate (He et al., 2014; Xie et al., 2015; Xue et al., 2016). Size-segregated particle samples in Beijing have shown that a considerable amount of sulfate is distributed in the coarse mode with particle diameters ranging from 2.1 to $9 \mu \mathrm{m}$, but sulfate peak concentrations still occur in the fine mode with particle diameters ranging from 0.43 to $1.1 \mu \mathrm{m}$ (Tian et al., 2016). Oxidation of sulfite by $\mathrm{NO}_{2}$ in aerosol water has also been proposed to contribute considerably to the sulfate production 


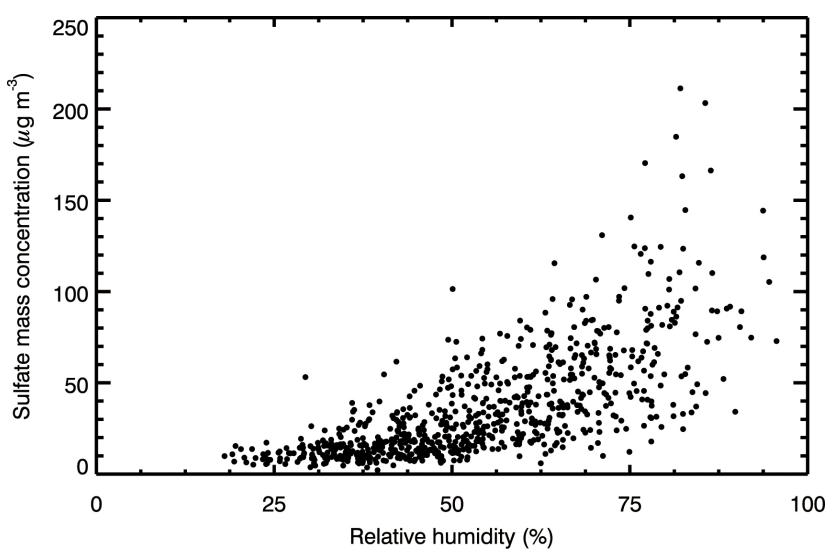

Figure 4. Scatter plot of the observed relative humidity with sulfate mass concentrations at the IEECAS site in Xi' an during the wintertime from 2003 to 2011.

when $\mathrm{NH}_{3}$ concentrations are sufficiently high (Pandis and Seifeld, 1989; Xie et al., 2015).

Laboratory or field studies have suggested that $\mathrm{O}_{3}$ or $\mathrm{Fe}^{3+}$ can oxidize sulfite to sulfate. Considering the low $\left[\mathrm{O}_{3}\right]$ during wintertime (Fig. 3), the oxidation of sulfite by $\mathrm{O}_{3}$ cannot constitute the main source of the wintertime sulfate. Mineral dust and coal combustion in China could provide sufficient iron. Measurements have indicated that mineral dust accounts for about $10 \%$ of $\mathrm{PM}_{2.5}$ in Beijing (He et al., 2014). Observations at an urban site in Ji'nan, China have also shown enhanced iron concentrations during haze episodes, ranging from 0.7 to $5.5 \mu \mathrm{g} \mathrm{m}^{-3}$, which are primarily emitted from steel smelting and coal combustion (Wang et al., 2012). Figure 5 shows the scatter plot of the wintertime $\mathrm{PM}_{2.5}$ and iron at IEECAS site from 2003 to 2010. The iron mass concentration generally increases with $\left[\mathrm{PM}_{2.5}\right]$, varying from 0.1 to $10 \mu \mathrm{g} \mathrm{m}^{-3}$, but does not correlate well with $\left[\mathrm{PM}_{2.5}\right.$ ] with the correlation coefficient of 0.34 , showing considerable background iron contributions. We assume that $1 \%$ of iron in Xi' an is dissolved in aerosol water and $1 \%$ of dissolved iron is in the $\mathrm{Fe}^{3+}$ oxidation state (Alexander et al., 2009). When the aerosol water concentration varies from 100 to $1000 \mu \mathrm{g} \mathrm{m}^{-3}$, the $\mathrm{Fe}^{3+}$ concentrations in Xi' an are between 0.18 and $180 \mu \mathrm{M}$, providing favorable conditions for the oxidation of adsorbed sulfite (Seinfeld and Pandis, 2006).

Here, we propose a $\mathrm{SO}_{2}$ heterogeneous reaction parameterization in which the $\mathrm{SO}_{2}$ oxidation in aerosol water by $\mathrm{O}_{2}$ catalyzed by $\mathrm{Fe}^{3+}$ is limited by mass transfer resistances in the gas-phase and the gas-particle interface.

$\mathrm{S}(\mathrm{IV})+\frac{1}{2} \mathrm{O}_{2} \stackrel{\mathrm{Fe}^{3+}}{\longrightarrow} \mathrm{S}(\mathrm{VI})$

When the solution $\mathrm{pH}$ is between 5.0 and 7.0, the oxidation reaction is second order in dissolved iron and first order in S(IV) and can be expressed as follows (Seinfeld and Pandis,

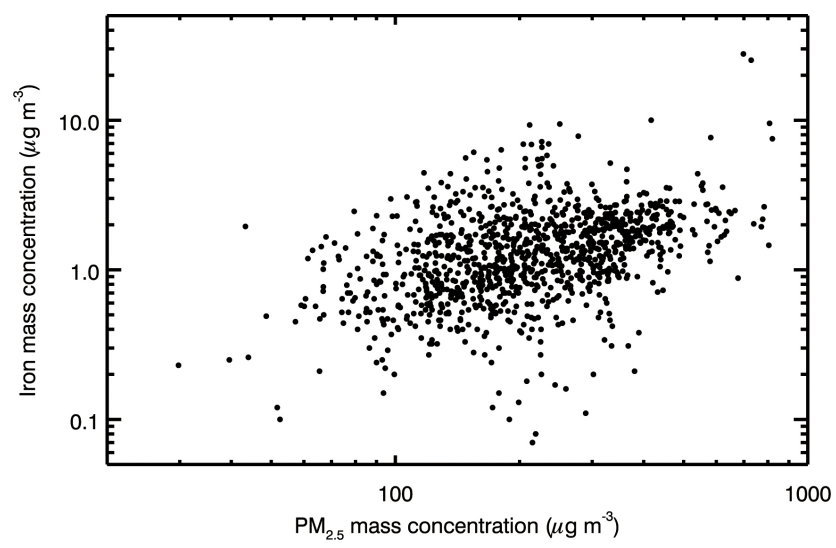

Figure 5. Scatter plot of the observed $\mathrm{PM}_{2.5}$ with iron mass concentrations at IEECAS site in Xi'an during the wintertime from 2003 to 2011 .

2006):

$-\frac{\mathrm{d}[\mathrm{S}(\mathrm{IV})]}{\mathrm{d} t}=1 \times 10^{-3}[\mathrm{~S}(\mathrm{IV})] 5.0<\mathrm{pH}<6.0$

$-\frac{\mathrm{d}[\mathrm{S}(\mathrm{IV})]}{\mathrm{d} t}=1 \times 10^{-4}[\mathrm{~S}(\mathrm{IV})] \mathrm{pH} \sim 7.0$,

where [S(IV)] is the sulfite (S(IV)) concentration. The measured $\mathrm{SO}_{2}$ mass accommodation coefficient on aqueous surfaces is around 0.1 (Worsnop et al., 1989). Due to sufficient $\mathrm{NH}_{3}$ and presence of mineral dust in the atmosphere in northern China, the calculated $\mathrm{pH}$ in aerosol water is between 5.0 and 7.0 (Cao et al., 2013). The $\mathrm{SO}_{2}$ uptake coefficient on aerosol water surface is estimated to be about $10^{-4}-10^{-5}$ if the sulfite oxidation is catalyzed by $\mathrm{Fe}^{3+}$. The sulfate heterogeneous formation from $\mathrm{SO}_{2}$ is therefore parameterized as a first-order irreversible uptake by aerosols, with a reactive uptake coefficient of $0.5 \times 10^{-4}$, assuming that there is enough alkalinity to maintain the high iron-catalyzed reaction rate:

$\frac{\mathrm{d}\left[\mathrm{SO}_{2}\right]}{\mathrm{d} t}=-\left(\frac{1}{4} \gamma_{\mathrm{SO}_{2}} v_{\mathrm{SO}_{2}} A_{\mathrm{w}}\right)\left[\mathrm{SO}_{2}\right]$,

where $\left[\mathrm{SO}_{2}\right]$ is the $\mathrm{SO}_{2}$ concentration, $A_{\mathrm{w}}$ is the aerosol water surface area, $\gamma_{\mathrm{SO}_{2}}$ is the $\mathrm{SO}_{2}$ reactive uptake coefficient, and $v_{\mathrm{SO}_{2}}$ is the $\mathrm{SO}_{2}$ thermal velocity. The aerosol hygroscopic growth is directly predicted by ISORROPIA (Version 1.7) in the model, and the aerosol water surface area is scaled from the calculated wet aerosol surface area using the thirdmoment of aerosol species. Considering that $\mathrm{O}_{3}$ and $\mathrm{NO}_{2}$ also play a considerable role in the sulfite oxidation when $\mathrm{pH}$ is high (Pandis and Seinfeld, 1989), future studies are needed to consider the $\mathrm{O}_{3}$ and $\mathrm{NO}_{2}$ contribution to the sulfate formation.

A box model is devised to interpret the rapid growth of sulfate observed at IEECAS site during winter 2013 in Xi'an. 
Table 2. Box model configurations.

\begin{tabular}{lrrr}
\hline Time $(\mathrm{BJT})$ & $07: 00-08: 00$ & $08: 00-09: 00$ & $09: 00-10: 00$ \\
\hline Temperature $\left({ }^{\circ} \mathrm{C}\right)$ & -3.7 & -3.2 & -2.1 \\
$\mathrm{SO}_{2}$ concentration $\left(\mu \mathrm{g} \mathrm{m}^{-3}\right)$ & 10.7 & 10.4 & 25.5 \\
${\text { Nitrate concentration }\left(\mu \mathrm{g} \mathrm{m}^{-3}\right)^{*}}_{\text {Ammonium concentration }\left(\mu \mathrm{g} \mathrm{m}^{-3}\right)^{*}}$ & 67.6 & 70.1 & 69.1 \\
& 65.2 & 76.0 & 91.9 \\
\hline
\end{tabular}

* The HR-ToF-AMS measures sulfate, nitrate, and ammonium aerosols with a time resolution of $1 \mathrm{~min}$. The high temporal resolution nitrate and ammonium are used to constrain the box model and the hourly average is presented in the table.

In this model, the proposed heterogeneous reaction of $\mathrm{SO}_{2}$ involving aerosol water (hereafter referred to as $\mathrm{HRSO}_{2}$ ) parameterization is included and ISORROPIA (Version 1.7) is used to simulate sulfate, nitrate, ammonium aerosols, and aerosol water. In addition, inorganic aerosols are represented by a two-moment modal approach with a lognormal size distribution. A severe haze episode occurred from 16 to $25 \mathrm{De}-$ cember 2013 in GZB, with the average observed $\left[\mathrm{PM}_{2.5}\right.$ ] exceeding $400 \mu \mathrm{g} \mathrm{m}^{-3}$ during the period from 23 to $25 \mathrm{De}-$ cember 2013. The HR-ToF-AMS measured sulfate concentrations reaching about $250 \mu \mathrm{g} \mathrm{m}^{-3}$ in the morning on 23 December and, in particular, the observed sulfate concentration increased from $132 \mu \mathrm{g} \mathrm{m}^{-3}$ at 07:30 BJT to $240 \mu \mathrm{g} \mathrm{m}^{-3}$ at $09: 30 \mathrm{BJT}$. The box model is utilized to simulate the rapid sulfate growth from 07:30 to 09:30 BJT, constrained by the observed temperature, $\mathrm{SO}_{2}$, nitrate, and ammonium (Table 2). There was no RH observation at the IEECAS site; the observed RH at adjacent meteorological stations ranged from 93 to $99 \%$ during the time period. In addition, the atmosphere was calm and stable during the simulation period due to the control of a high pressure system over GZB, so the horizontal transport is not considered. Various RHs from 93 to $99 \%$ are used to calculate the sulfate growth in the box model. Figure 6 shows the calculated and observed sulfate concentrations from 07:30 to 09:30 on 23 December 2013. The RH significantly influences the sulfate formation and the sulfate concentrations increase nonlinearly with the RH. When the RH is $93 \%$, the sulfate concentration is increased by $22.7 \mu \mathrm{g} \mathrm{m}^{-3}$ after $2 \mathrm{~h}$ integration, whereas the enhanced sulfate concentration reaches $216.6 \mu \mathrm{g} \mathrm{m}^{-3}$ when the RH is $99 \%$. The simulated sulfate concentrations are best fit for the observation when the RH is $98 \%$. It is worth noting that, when $\mathrm{RH}$ is high (i.e., exceeding $95 \%$ or so), there is always the possibility of the presence of fog. Studies have demonstrated that, for every observed sulfate peak in the 1980s in Los Angeles, there is fog present (Pandis and Seinfeld, 1989; Pandis et al., 1992). Hence, the box model simulations with RH ranging from 93 to $99 \%$ strongly suggest that there was at least some patchy fog in the area, which would provide sufficient water for the rapid iron-catalyzed reaction. Further studies need to be performed to investigate the possible contributions of the patchy fog to the sulfate formation.

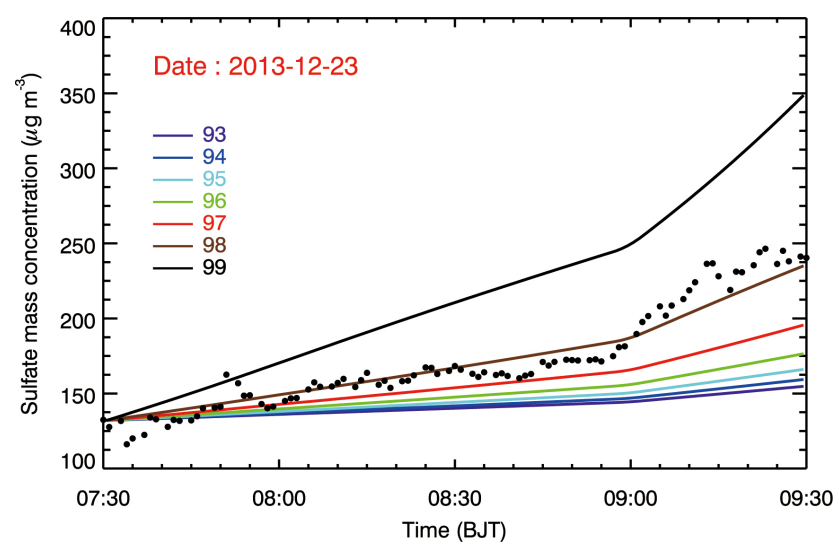

Figure 6. Sulfate growth simulated by the box model with the $\mathrm{HRSO}_{2}$ parameterization under various relative humidity conditions at IEECAS site in Xi' an from 07:30 to 09:30 BJT on 23 December 2013. The black dots denote the HR-ToF-AMS measurement and the solid lines with different colors represent the box model simulations under different relative humidities.

\subsection{Sulfate simulations in GZB and BTH}

The proposed $\mathrm{HRSO}_{2}$ parameterization is further incorporated into the WRF-CHEM model to simulate sulfate aerosols. Two simulations are performed for GZB and BTH respectively, including the base case (hereafter referred to as B-case) without the $\mathrm{HRSO}_{2}$ parameterization and the enhanced oxidation case (hereafter referred to as E-case) with the $\mathrm{HRSO}_{2}$ parameterization. In Figs. 7 and 8, we present the spatial distributions of calculated and observed near-surface $\left[\mathrm{PM}_{2.5}\right]$ at 00:00 BJT in the E-case on 6 selected days representing the haze development in GZB and BTH, along with the simulated wind fields. In general, the predicted $\mathrm{PM}_{2.5}$ spatial patterns agree well with the observations at the ambient monitoring sites in GZB and BTH. The model reproduces the high $\left[\mathrm{PM}_{2.5}\right]$ in GZB well, although it tends to underestimate the observation in the west of GZB. Due to the specific topography, when the northeastern winds are prevalent in GZB, pollutants tend to accumulate, and simulated and observed $\left[\mathrm{PM}_{2.5}\right]$ can be up to $500 \mu \mathrm{g} \mathrm{m}^{-3}$. When the northern winds are intensified on 26 December 2013, the pollutants start to be transported outside of GZB. In BTH, 

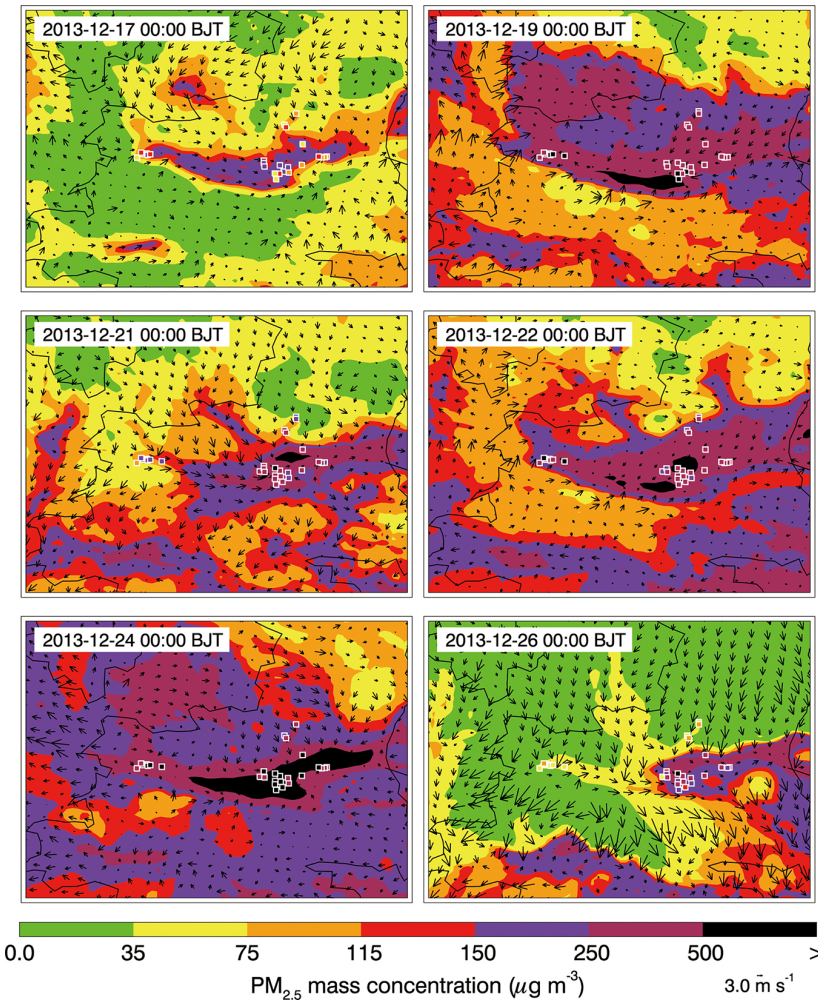

Figure 7. Pattern comparison of simulated vs. observed nearsurface $\mathrm{PM}_{2.5}$ at 00:00 BJT during the 6 selected days in GZB from 16 to 27 December 2013. Colored circles are $\mathrm{PM}_{2.5}$ observations, color contours are $\mathrm{PM}_{2.5}$ simulations in the E-case, black arrows indicate simulated surface winds in the E-case.

simulated weak winds cause severe $\mathrm{PM}_{2.5}$ pollution, with $\left[\mathrm{PM}_{2.5}\right]$ frequently exceeding $250 \mu \mathrm{g} \mathrm{m}^{-3}$ in most areas of BTH, which is consistent with the observations over monitoring sites. Hence, in general, the model reproduces the haze formation in GZB and BTH reasonably well.

In the present study, ISORROPIA (Version 1.7) is employed to predict the thermodynamic equilibrium between the sulfate-nitrate-ammonium-water aerosols and their gasphase precursors $\mathrm{H}_{2} \mathrm{SO}_{4}-\mathrm{HNO}_{3}-\mathrm{NH}_{3}$-water vapor. $\mathrm{SO}_{2}$ and $\mathrm{NO}_{2}$ are the precursors of $\mathrm{H}_{2} \mathrm{SO}_{4}$ and $\mathrm{HNO}_{3}$, so it is imperative to evaluate the $\mathrm{SO}_{2}$ and $\mathrm{NO}_{2}$ simulations using the measurements to more reasonably calculate inorganic aerosol concentrations.

Figures 9 and 10 show the temporal profiles of observed and simulated near-surface $\left[\mathrm{NO}_{2}\right]$ and $\left[\mathrm{SO}_{2}\right]$ averaged over monitoring sites in GZB from 16 to 27 December 2013 and in BTH from 13 to 21 January 2014, respectively. The model performs well when simulating the $\left[\mathrm{NO}_{2}\right]$ temporal variations compared with observations in GZB and BTH, both of which have an IOA of 0.91 in the E-case. The difference in the simulated $\left[\mathrm{NO}_{2}\right]$ in the B-case and E-case is minor, and the average $\left[\mathrm{NO}_{2}\right]$ is increased by $0.69 \%$ in GZB and decreased by $0.1 \%$ in $\mathrm{BTH}$ in the E-case compared to the
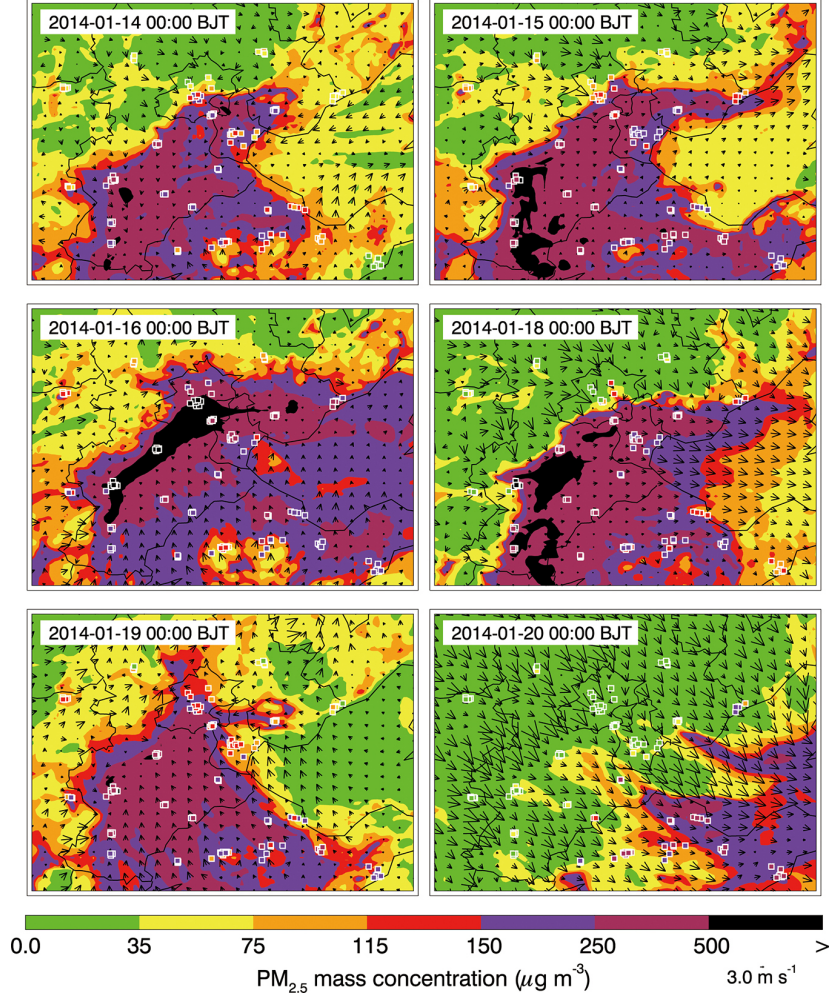

Figure 8. Same as Fig. 7, but in BTH from 13 to 21 January 2014.

B-case, showing that the impact of the $\mathrm{HRSO}_{2}$ parameterization on $\mathrm{NO}_{2}$ simulations is not significant in GZB and $\mathrm{BTH}$. Although the model replicates the temporal variations of $\left[\mathrm{SO}_{2}\right]$ compared to the measurements in GZB and NCP in the E-case with IOAs of around 0.80, the model biases still exist. The model generally underestimates $\left[\mathrm{SO}_{2}\right]$ in GZB and $\mathrm{BTH}$, with MBs of -3.4 and $-0.8 \mu \mathrm{g} \mathrm{m}^{-3}$. One of the possible reasons for $\mathrm{SO}_{2}$ simulation biases is that large amounts of $\mathrm{SO}_{2}$ are emitted from point sources, such as power plants or agglomerated industrial zones, and the transport of $\mathrm{SO}_{2}$ from point sources is more sensitive to the wind field simulation uncertainties (Bei et al., 2012, 2016). The $\mathrm{HRSO}_{2}$ parameterization generally improves the $\mathrm{SO}_{2}$ simulations by accelerating $\mathrm{SO}_{2}$ conversions to sulfate, decreasing the $\mathrm{MB}$ from $11.0 \mu \mathrm{g} \mathrm{m}^{-3}$ in the B-case to $-3.4 \mu \mathrm{g} \mathrm{m}^{-3}$ in the E-case in GZB and $5.0 \mu \mathrm{g} \mathrm{m}^{-3}$ in the B-case to $-0.8 \mu \mathrm{g} \mathrm{m}^{-3}$ in the E-case in BTH. On average, inclusion of the $\mathrm{HRSO}_{2}$ parameterization decreases the $\left[\mathrm{SO}_{2}\right]$ by 15.9 and $3.4 \%$ in GZB and $\mathrm{BTH}$, respectively. Overall, the model performs well when simulating the $\mathrm{NO}_{2}$ and $\mathrm{SO}_{2}$ temporal variations against the measurements in GZB and BTH in the E-case. Due to a lack of routine measurements of $\mathrm{NH}_{3}$ in GZB and $\mathrm{BTH}$, the evaluation of the model performance on $\mathrm{NH}_{3}$ is not provided in the present study. It is imperative that future studies are performed to evaluate the model performance on $\mathrm{NH}_{3}$, which plays an important role in the sulfate formation (Wang et al., 2016). 

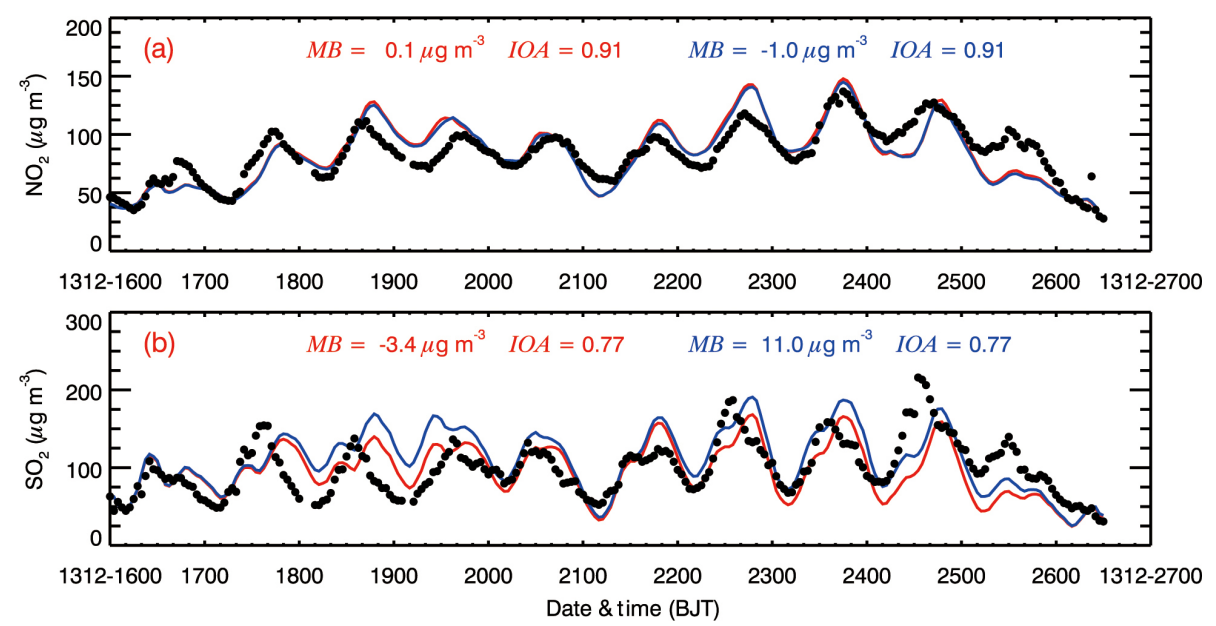

Figure 9. Comparison of measured and predicted diurnal profiles of near-surface hourly (a) $\mathrm{NO}_{2}$ and (b) $\mathrm{SO}_{2}$ averaged over all ambient monitoring sites in GZB from 16 to 27 December 2013. The black dots correspond to the observations, and the solid red and blue lines are the simulations in the E-case and B-case, respectively.

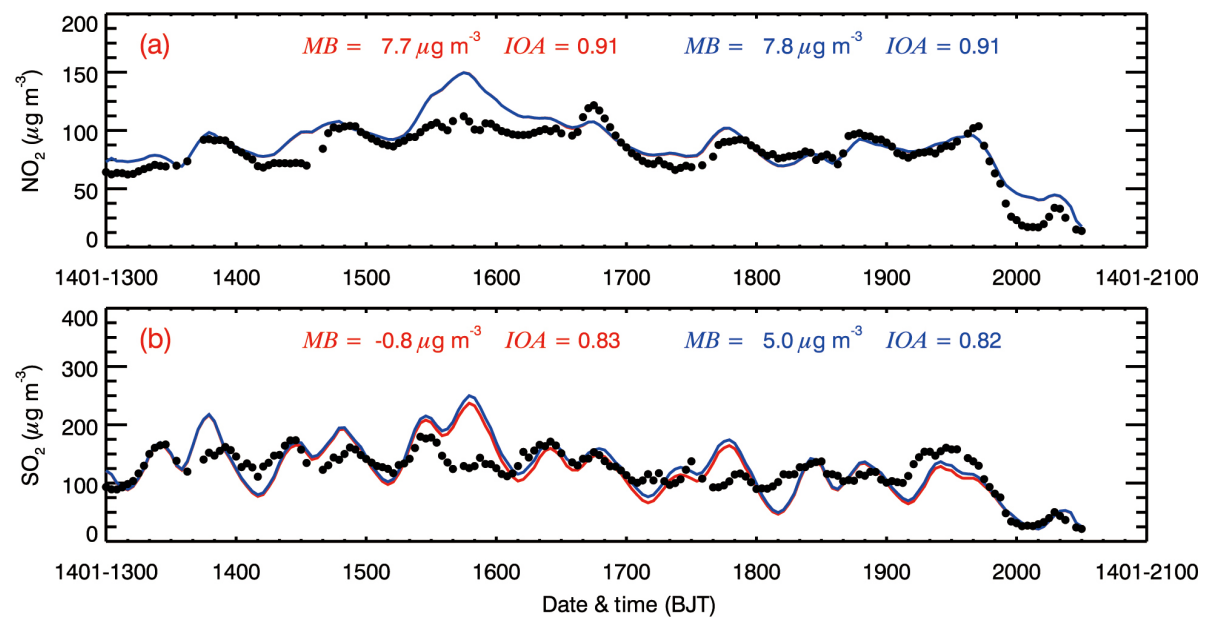

Figure 10. Same as Fig. 9, but in BTH from 13 to 21 January 2014.

Figures 11 and 12 display the simulated and observed inorganic aerosol variations in Xi' an from 16 to 27 December 2013 and in Beijing from 13 to 21 January 2014, respectively. In Xi'an, the observed sulfate mass concentrations range from 50 to $250 \mu \mathrm{g} \mathrm{m}^{-3}$, constituting the second most important $\mathrm{PM}_{2.5}$ component during the episode. The $\mathrm{HRSO}_{2}$ parameterization substantially improves the sulfate simulations in the E-case compared to those in the B-case against the measurements. In the B-case, the sulfate concentrations are remarkably underestimated, with a MB of $-72.4 \mu \mathrm{g} \mathrm{m}^{-3}$ (Table 3). However, in the E-case, the WRF-CHEM model generally yields the observed sulfate variations during the 11day episode, with a MB of $-17.0 \mu \mathrm{g} \mathrm{m}^{-3}$ and an IOA of 0.89 , and the average sulfate concentration is enhanced by $172 \%$ compared to the B-case. In Beijing, the model also reproduces the observed sulfate variations reasonably well during the 7-day episode in the E-case, with a MB of $-0.8 \mu \mathrm{g} \mathrm{m}^{-3}$ and an IOA of 0.88 (Table 3), but cannot adequately predict the observed sulfate peaks. The average sulfate concentration is enhanced by $58.4 \%$ in the E-case compared to the B-case in Beijing. The improvement of sulfate simulations caused by the $\mathrm{HRSO}_{2}$ parameterization in Beijing is not as obvious as that in Xi' an due to the very humid conditions in GZB during the simulation period, which facilitate the rapid conversion of $\mathrm{SO}_{2}$ to sulfate and cause the $\mathrm{SO}_{2}$ heterogeneous conversion to be the dominant sulfate source.

Considering the importance of $\mathrm{RH}$ in the $\mathrm{SO}_{2}$ heterogeneous oxidation, Fig. 13 shows the simulated and observed RH diurnal profiles in Xi' an from 16 to 27 December 2013 and in Beijing from 13 to 21 January 2014. The model generally performs reasonably well when simulating the observed $\mathrm{RH}$, with IOAs of 0.80 for Xi' an and 0.76 for Beijing. Overall, the model is subject to overestimating the RH, especially in Beijing, but captures the observed peaks of the RH in Bei- 

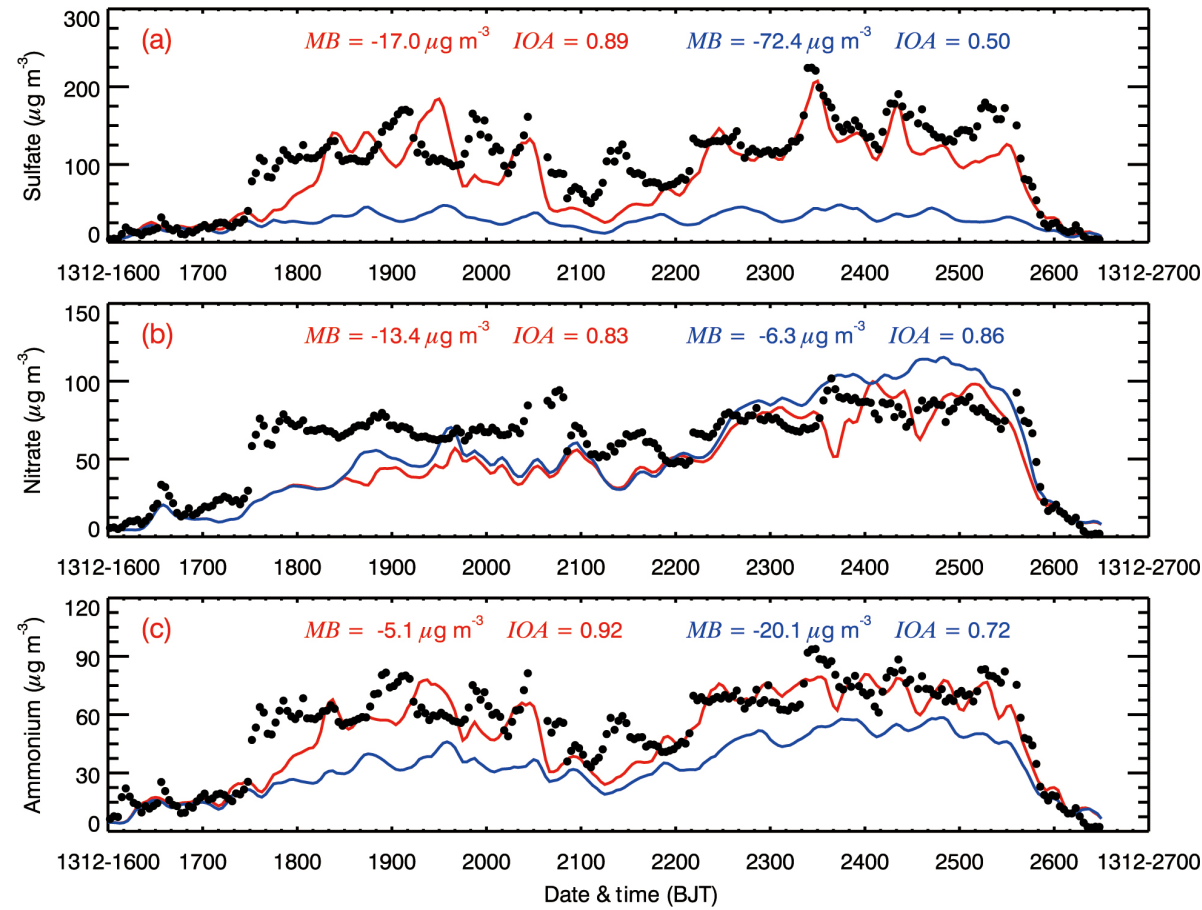

Figure 11. Comparison of measured and simulated diurnal profiles of inorganic aerosols of (a) sulfate, (b) nitrate, and (c) ammonium in Xi' an from 16 to 27 December 2013. The black dots represent the observations, and the solid red and blue lines denote the simulations in the E-case and B-case, respectively.
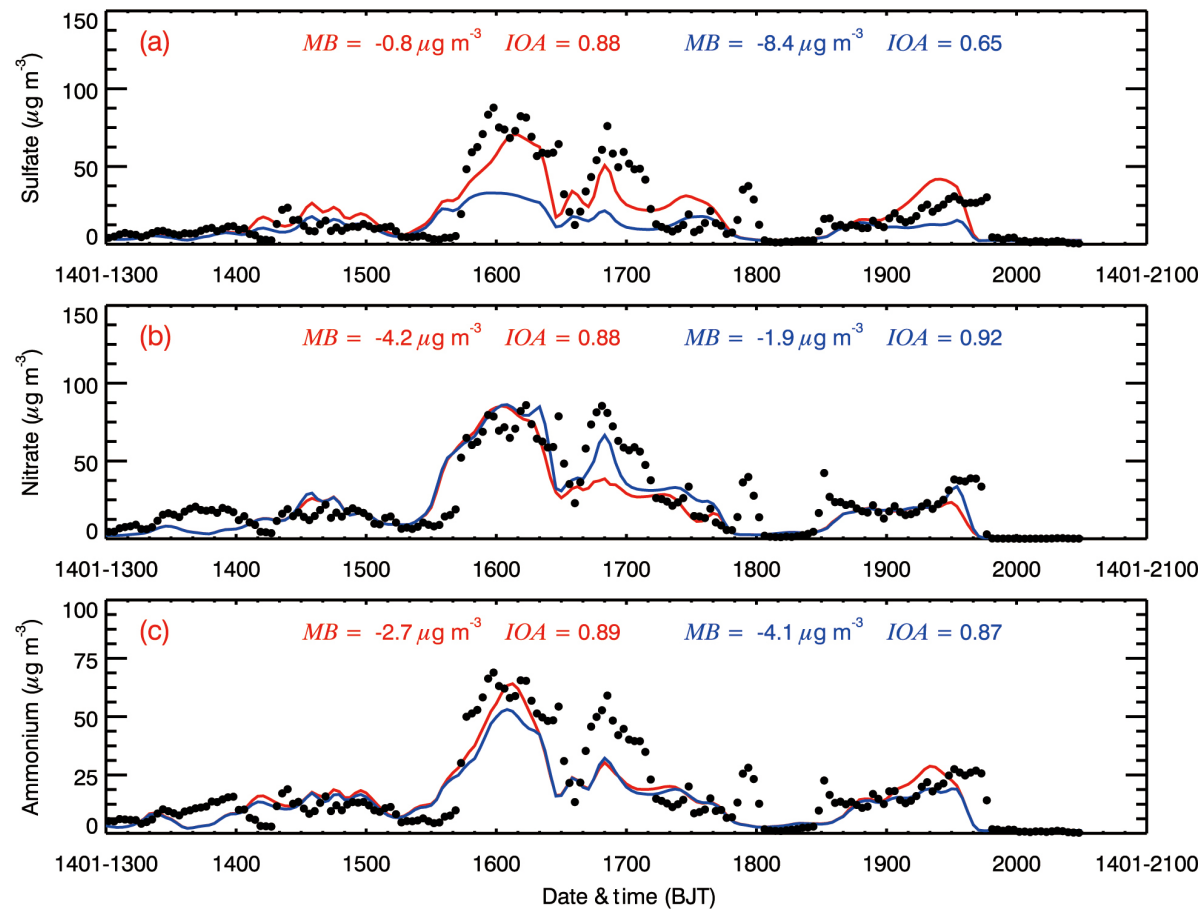

Figure 12. Same as Fig. 11, but in Beijing from 13 to 21 January 2014. 
Table 3. Statistical comparisons of simulated and measured sulfate, nitrate, and ammonium concentrations in Xi' an and Beijing.

\begin{tabular}{llrrrr}
\hline City & Species & \multicolumn{2}{c}{ E-case } & \multicolumn{2}{c}{ B-case } \\
\cline { 3 - 6 } & & $\mathrm{MB}\left(\mu \mathrm{g} \mathrm{m}^{-3}\right)$ & $\mathrm{IOA}$ & $\mathrm{MB}\left(\mu \mathrm{g} \mathrm{m}^{-3}\right)$ & $\mathrm{IOA}$ \\
\hline \multirow{3}{*}{ Xi'an } & Sulfate & -17.0 & 0.89 & -72.4 & 0.50 \\
& Nitrate & -13.4 & 0.83 & -6.3 & 0.86 \\
& Ammonium & -5.1 & 0.92 & -20.1 & 0.72 \\
\hline \multirow{3}{*}{ Beijing } & Sulfate & -0.8 & 0.88 & -8.4 & 0.65 \\
& Nitrate & -4.2 & 0.88 & -1.9 & 0.92 \\
& Ammonium & -2.7 & 0.89 & -4.1 & 0.87 \\
\hline
\end{tabular}
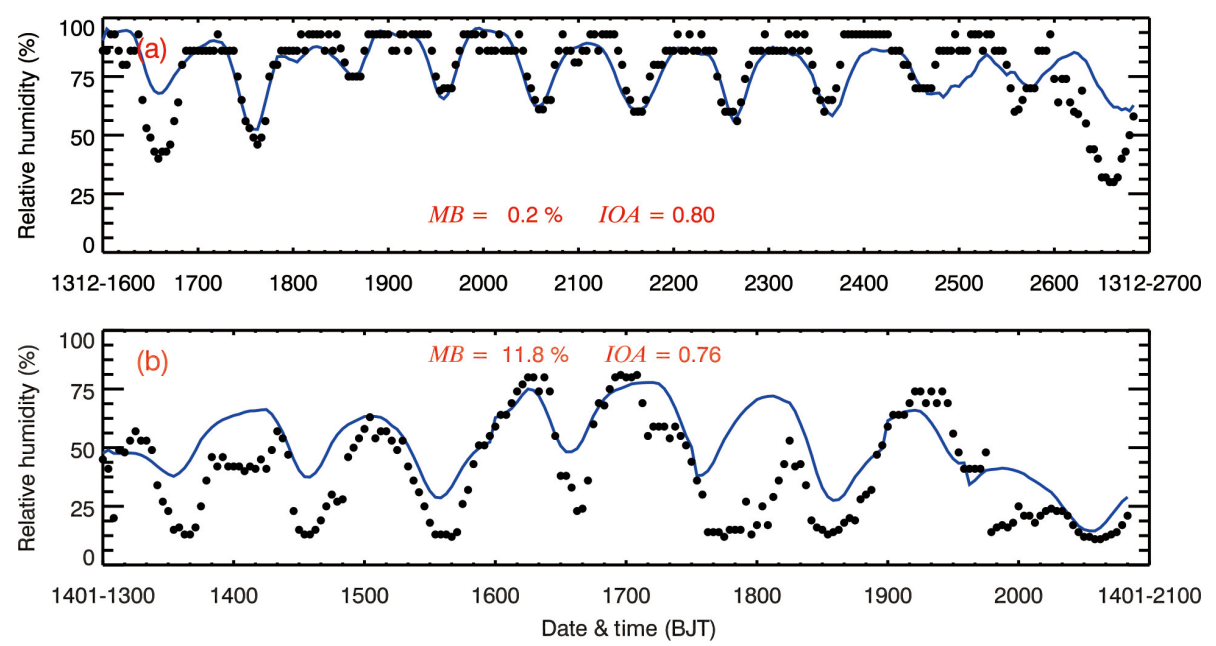

Figure 13. Comparison of measured (black dots) and simulated (blue lines, in the E-case) diurnal profiles of the relative humidity (a) in Xi'an from 16 to 27 December 2013 and (b) in Beijing from 13 to 21 January 2014.

jing and Xi' an well. The RH biases considerably affect the sulfate simulations. The underestimation of the high RH generally corresponds to the underestimation of the sulfate concentration, i.e., during nighttime on 15 and 16 January 2014 in Beijing, and in the morning from 23 to 25 December 2013 in Xi' an. It is worth noting that, during the two episodes, the $\mathrm{SO}_{2}$ oxidation by $\mathrm{OH}$ of the sulfate formation is not important. We have performed additional sensitivity simulations in which only the direct emissions of sulfate are considered. Comparisons of the sensitivity simulation with the B-case show that the $\mathrm{SO}_{2}$ oxidation by $\mathrm{OH}$ can explain about 5.1 and $11.7 \%$ of the observed sulfate concentrations in $\mathrm{Xi}^{\prime}$ an and Beijing on average, respectively.

Although the IOA for nitrate aerosols is 0.83 , the nitrate underestimation is rather large from 17 to 21 December 2013 in Xi' an in the E-case. The nitrate simulations are improved in Beijing compared to those in Xi' an, with a MB of $-4.2 \mu \mathrm{g} \mathrm{m}^{-3}$ and an IOA of 0.88 in the E-case. The nitrate simulations in the B-case are slightly better than those in the E-case, caused by the underestimation of sulfate aerosols in the $\mathrm{B}$-case, which is favorable for more $\mathrm{HNO}_{3}$ to exist in the aerosol phase. The inclusion of the $\mathrm{HRSO}_{2}$ parameteri- zation deceases the simulated nitrate concentration by 15.3 and $19.5 \%$ in Xi' an and Beijing, respectively, on average. The model performs well when predicting the ammonium aerosols in Xi' an and Beijing, with IOAs of around 0.90 in the E-case. The ammonium simulations in the E-case are improved compared to those in the B-case against the measurement, showing that sulfate aerosols play an important role in ammonium aerosol formation. The average ammonium concentration is enhanced by $36.8 \%$ in Xi' an and $7.2 \%$ in Beijing by the inclusion of the $\mathrm{HRSO}_{2}$ parameterization. Considering the substantial influence of simulated meteorological fields uncertainties on the aerosol species comparison at a single site (Bei et al., 2012), the $\mathrm{HRSO}_{2}$ parameterization performs reasonably well when simulating the observed inorganic aerosol variations in Xi' an and Beijing in the E-case.

Recently, Wang et al. (2016) have also elucidated a specific mechanism for the sulfite-sulfate conversion, in which oxidation of sulfite by $\mathrm{NO}_{2}$ in aerosol water in case of high $\mathrm{NH}_{3}$ concentrations contributes considerably to sulfate production. They have also pointed out the critical role of sulfate formation in haze formation in China through further promoting the formation of SOA and nitrate due to enhanced hy- 

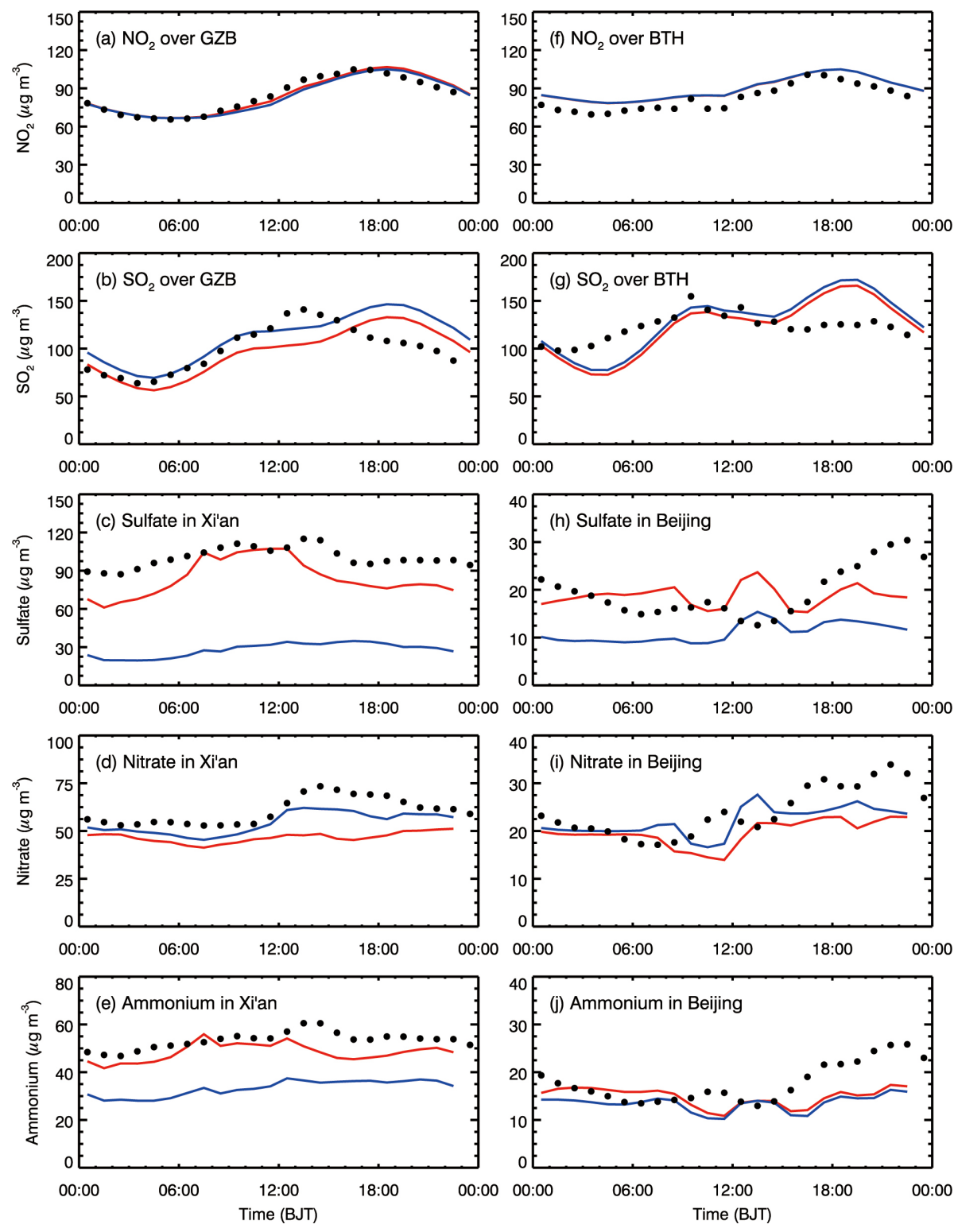

Figure 14. Observed and simulated diurnal cycles of mass concentrations of $\mathrm{NO}_{2}$ and $\mathrm{SO}_{2}$ averaged over GZB and $\mathrm{BTH}$ and the sulfate, nitrate, and ammonium aerosols in Xi' an and Beijing during the simulated episodes.

groscopicity. Zhang et al. (1995) have reported that the high concentration of nitrate is attributed to an efficient heterogeneous conversion of $\mathrm{NO}_{x}$ to $\mathrm{HNO}_{3}$ due to the hydrolysis of $\mathrm{N}_{2} \mathrm{O}_{5}$ on sulfate aerosols. Zhao et al. (2006) have investigated the heterogeneous chemistry of methylglyoxal with liquid $\mathrm{H}_{2} \mathrm{SO}_{4}$, showing that the hydration and oligomerization reactions of methylglyoxal are enhanced by sulfate formation due to the high dependence of these reactions on particle hygroscopicity. Therefore, future studies need to be performed to incorporate the specific mechanism into CTMs to improve sulfate, nitrate, and SOA simulations.

Figure 14 presents the observed and simulated diurnal cycles of mass concentrations of $\mathrm{NO}_{2}$ and $\mathrm{SO}_{2}$ averaged over GZB and BTH and the sulfate, nitrate, and ammonium aerosols in $\mathrm{Xi}$ ' an and Beijing during the simulated episodes. The WRF-CHEM model performs well when simulating the $\mathrm{NO}_{2}$ diurnal cycles compared to measurements over GZB and $\mathrm{BTH}$ in the E-case. The model also reasonably reproduces the observed diurnal cycles of $\mathrm{SO}_{2}$ over GZB, sulfate, nitrate, and ammonium aerosols in $\mathrm{Xi}$ ' an in the E-case. In particular, the sulfate simulations are significantly improved in the E-case compared with the B-case against the measurements. However, the model does not predict the observed diurnal cycles of sulfate, nitrate, and ammonium aerosols in Beijing well, which shows the model biases when simulating the southern or eastern wind fronts. 


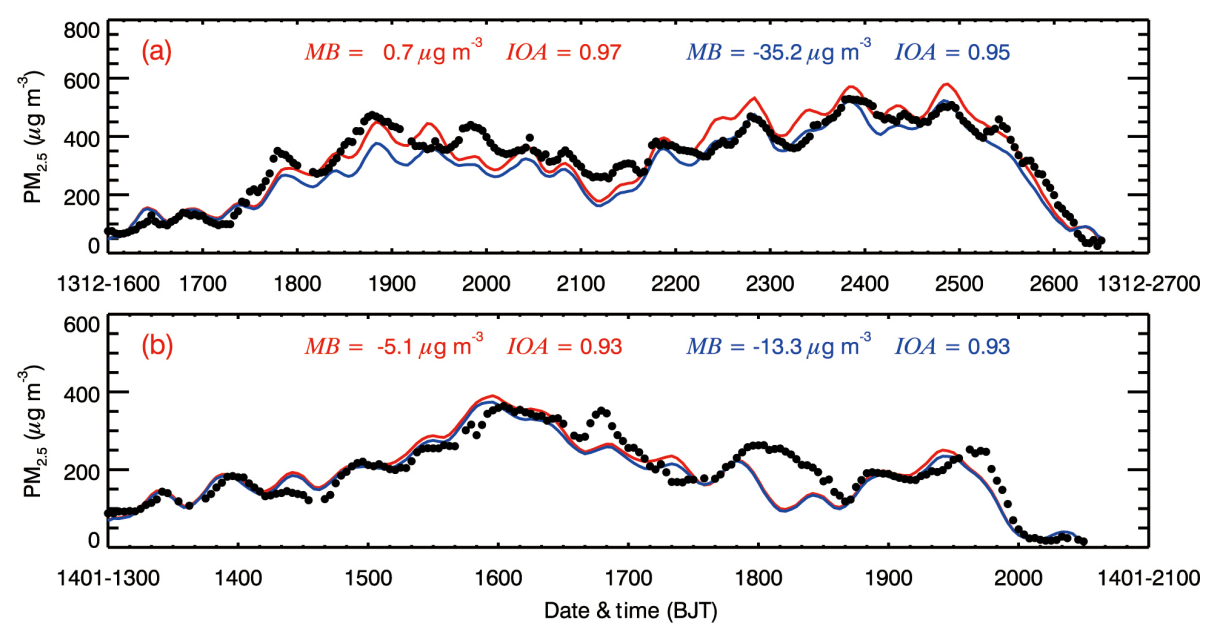

Figure 15. Comparison of measured and predicted diurnal profiles of near-surface hourly $\mathrm{PM}_{2.5}$ mass concentration averaged over all ambient monitoring stations (a) in GZB from 16 to 27 December 2013 and (b) in BTH from 13 to 21 January 2014. The black dots represent the observations, and the solid red and blue lines are the simulations in the E-case and B-case, respectively.

As one of the most important components of $\mathrm{PM}_{2.5}$, reasonable representation of sulfate heterogeneous formation in CTMs is imperative to $\mathrm{PM}_{2.5}$ simulations and predictions. Figure 15 presents the temporal profiles of observed and simulated near-surface $\left[\mathrm{PM}_{2.5}\right]$ averaged over monitoring sites in GZB from 16 to 27 December 2013 and in BTH from 13 to 21 January 2014, respectively. Inclusion of the $\mathrm{HRSO}_{2}$ parameterization in the E-case improves the ability of the model to reproduce the $\mathrm{PM}_{2.5}$ measurements in GZB and BTH. In GZB, due to very humid conditions which facilitate the heterogeneous sulfate formation during the episode, the simulated $\mathrm{PM}_{2.5}$ mass concentrations are increased by more than $40 \mu \mathrm{g} \mathrm{m}^{-3}$ in the E-case compared to the B-case with an average increase of $12.3 \%$, and are more consistent with the measurements. The $\mathrm{HRSO}_{2}$ parameterization also improves the $\mathrm{PM}_{2.5}$ simulations in $\mathrm{BTH}$, with an average increase of less than $3.0 \%$, reducing the underestimation from around -13.3 to $-5.1 \mu \mathrm{g} \mathrm{m}^{-3}$. The $\mathrm{HRSO}_{2}$ parameterization considerably enhances the $\left[\mathrm{PM}_{2.5}\right]$ in GZB (Fig. 16a), with an average $\left[\mathrm{PM}_{2.5}\right]$ contribution of about $10-50 \mu \mathrm{g} \mathrm{m}^{-3}$ from 16 to 27 December 2013. The average $\left[\mathrm{PM}_{2.5}\right]$ contributions of the sulfate heterogeneous formation are around $2-30 \mu \mathrm{g} \mathrm{m}^{-3}$ in BTH (Fig. 16b) from 13 to 21 January 2014, lower than those in GZB.

The sulfate aerosol significantly affects nitrate and ammonium formation in the atmosphere due to its stability and the deliberate thermodynamic equilibrium between inorganic aerosols and their precursors. The simulated hourly nearsurface sulfate concentrations in the E-case during the whole episode are first subdivided into 20 bins with the interval of $5 \mu \mathrm{g} \mathrm{m}^{-3}$. Inorganic aerosols and $\mathrm{PM}_{2.5}$ concentrations in the $\mathrm{B}$-case and E-case are assembled as the bin sulfate concentrations in the E-case following the grid cells respectively, and an average of inorganic aerosols and $\mathrm{PM}_{2.5}$ concentrations in

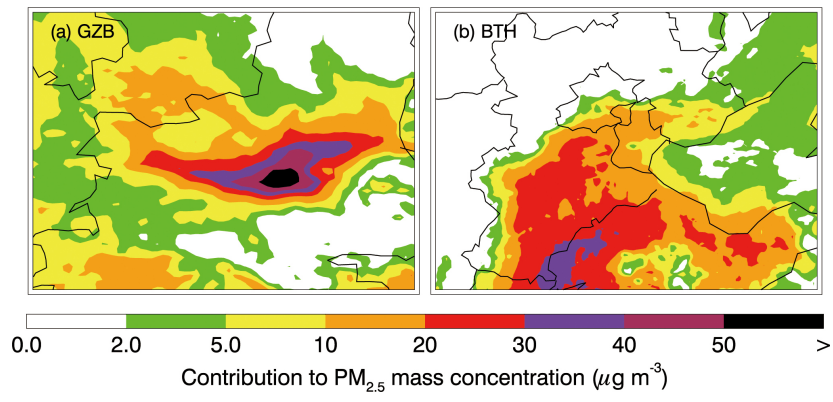

Figure 16. Distribution of the average near-surface $\mathrm{PM}_{2.5}$ contribution due to the $\mathrm{SO}_{2}$ heterogeneous reactions in GZB and BTH during the simulated episodes.

each bin are calculated. Figures 17 and 18 show the impacts of the $\mathrm{HRSO}_{2}$ parameterization on the inorganic aerosols and $\mathrm{PM}_{2.5}$ simulations in GZB and NCP, respectively. The heterogeneous sulfate formation determines the sulfate level when the sulfate concentration in the E-case is more than $25 \mu \mathrm{g} \mathrm{m}^{-3}$, with the contribution exceeding $50 \%$ in GZB. However, in BTH, the heterogeneous sulfate formation plays a more important role in the sulfate level only when the sulfate concentration in the E-case exceeds $45 \mu \mathrm{g} \mathrm{m}^{-3}$. If the $\mathrm{HRSO}_{2}$ parameterization is not considered, the model generally predicts more nitrate and less ammonium aerosol (Figs. $17 \mathrm{~b}-\mathrm{c}$ and $18 \mathrm{~b}-\mathrm{c}$ ). In addition, the $\left[\mathrm{PM}_{2.5}\right]$ contributions of the heterogeneous sulfate formation exceed 5 and $10 \%$ when the simulated sulfate concentrations in the Ecase are more than 10 and $80 \mu \mathrm{g} \mathrm{m}^{-3}$ in GZB, respectively (Fig. 17d). However, in BTH, the contributions exceed $5 \%$ when the simulated sulfate concentrations in the E-case are higher than $50 \mu \mathrm{g} \mathrm{m}^{-3}$ (Fig. 18d). 

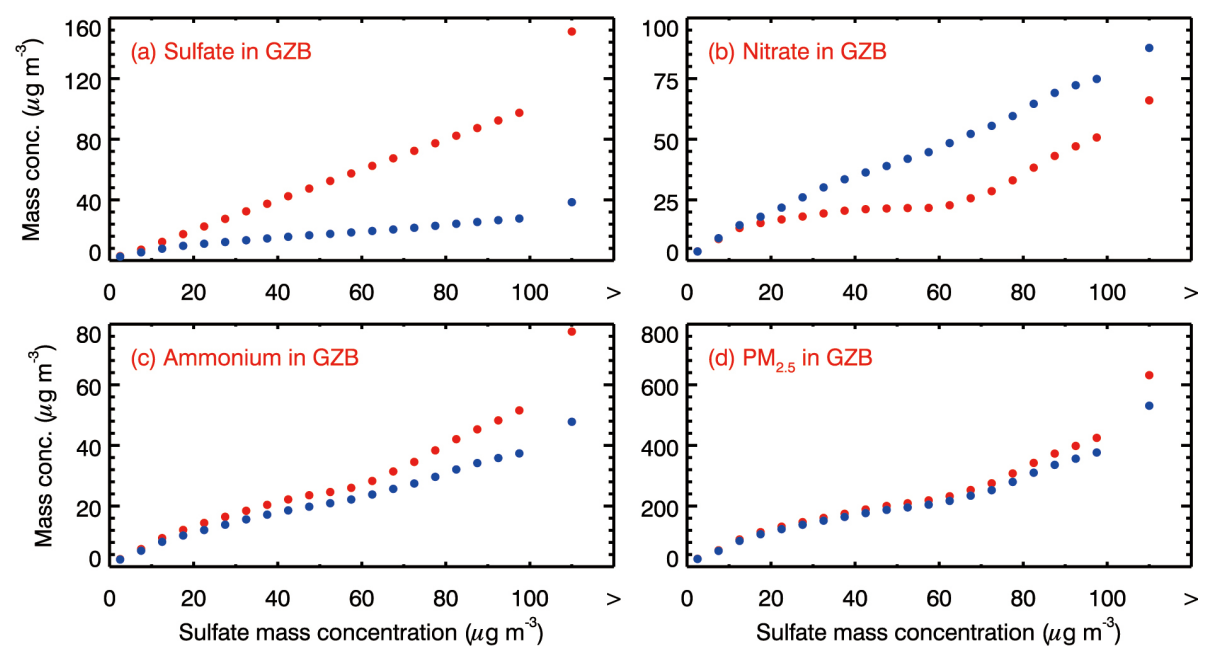

Figure 17. Average (a) sulfate, (b) nitrate, (c) ammonium, and (d) $\mathrm{PM}_{2.5}$ mass concentrations in GZB during the simulation period as a function of the sulfate mass concentration in the E-case. The red and blue dots represent average mass concentrations in the E-case and B-case, respectively.
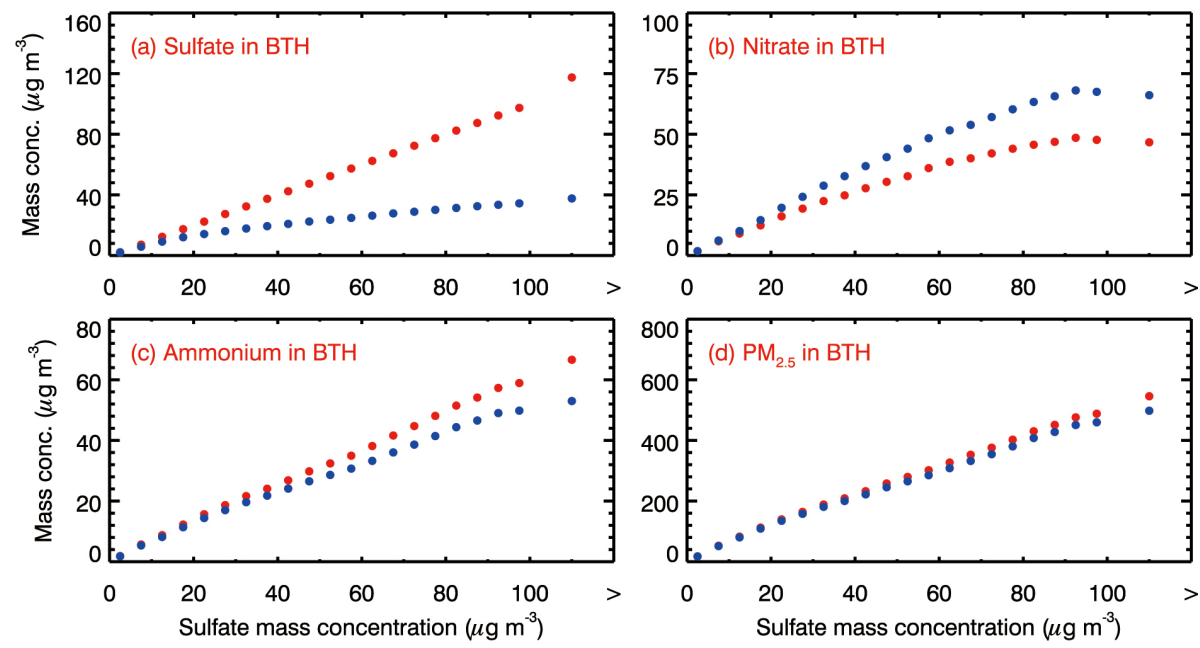

Figure 18. Same as Fig. 16, but in BTH from 13 to 21 January 2014.

\section{Summary and conclusions}

In the present study, a parameterization of sulfate heterogeneous formation involving aerosol water $\left(\mathrm{HRSO}_{2}\right)$ is developed based on daily filter measurements in $\mathrm{Xi}^{\prime}$ an since 2003. $\mathrm{A} \mathrm{SO}_{2}$ heterogeneous reaction parameterization has been proposed, in which the $\mathrm{SO}_{2}$ oxidation in aerosol water by $\mathrm{O}_{2}$ catalyzed by $\mathrm{Fe}^{3+}$ is limited by mass transfer resistances in the gas-phase and the gas-particle interface. The sulfate heterogeneous formation from $\mathrm{SO}_{2}$ is parameterized as a first-order irreversible uptake by aerosol water surfaces, with a reactive uptake coefficient of $0.5 \times 10^{-4}$ assuming that there is enough alkalinity to maintain the high iron-catalyzed reaction rate. A box model with the $\mathrm{HRSO}_{2}$ parameterization successfully reproduces the observed rapid sulfate formation at IEECAS site in $\mathrm{Xi}^{\prime}$ an.
The $\mathrm{HRSO}_{2}$ parameterization is implemented into the WRF-CHEM model to simulate sulfate aerosols. Two persistent heavy haze pollution episodes are simulated with and without the $\mathrm{SO}_{2}$ heterogeneous reaction: (1) 16 to $27 \mathrm{De}$ cember 2013 in GZB, and (2) 13 to 21 January 2014 in BTH. In general, the model performs reasonably well when simulating the $\mathrm{PM}_{2.5}$ distributions and the $\mathrm{NO}_{2}$ and $\mathrm{SO}_{2}$ temporal variations compared with observations in GZB and NCP. The $\mathrm{HRSO}_{2}$ parameterization improves the $\mathrm{SO}_{2}$ simulations by accelerating $\mathrm{SO}_{2}$ conversions to sulfate aerosols.

The $\mathrm{HRSO}_{2}$ parameterization substantially improves the sulfate simulations compared to the measurements in Xi' an and Beijing, particularly under humid conditions. In Xi'an, the sulfate concentrations are substantially underestimated when the $\mathrm{HRSO}_{2}$ parameterization is not considered in the 
simulations. Inclusion of the $\mathrm{HRSO}_{2}$ parameterization significantly enhances the sulfate formation, and the model generally produces the observed sulfate variations during the 11day episode. In Beijing, improvement in sulfate simulations with $\mathrm{HRSO}_{2}$ parameterization is not as obvious as in $\mathrm{Xi}$ ' an because of the very humid conditions in GZB during the simulation period. The $\mathrm{HRSO}_{2}$ parameterization also improves the ammonium simulations in Xi' an and Beijing compared to observations, as well as appreciably improving the $\mathrm{PM}_{2.5}$ simulations against the measurements over monitoring sites in GZB and NCP.

In summary, a reasonable representation of sulfate heterogeneous formation not only improves the $\mathrm{PM}_{2.5}$ simulations, but also helps to rationally verify the contribution of inorganic aerosols to $\mathrm{PM}_{2.5}$, providing the underlying basis for better understanding the haze formation and supporting the design and implementation of emission control strategies.

Data availability. The real-time $\mathrm{O}_{3}$ and $\mathrm{PM}_{2.5}$ are accessible to the public on the website http://106.37.208.233:20035/ (China MEP, 2013a). One can also access the historic profile of observed ambient pollutants by visiting http://www.aqistudy.cn/ (China MEP, 2013b).

Competing interests. The authors declare that they have no conflict of interest.

Acknowledgements. The authors would like to acknowledge Spyros Pandis for providing helpful discussions. This work was supported by the National Natural Science Foundation of China (No. 41275153) and supported by the "Strategic Priority Research Program" of the Chinese Academy of Sciences-Grant No. XDB05060500. Guohui Li is also supported by the "Hundred Talents Program" of the Chinese Academy of Sciences. Naifang Bei is supported by the National Natural Science Foundation of China (No. 41275101).

Edited by: R. Zhang

Reviewed by: two anonymous referees

\section{References}

Alexander, B., Park, R. J., Jacob, D. J., and Gong, S. L.: Transition metal-catalyzed oxidation of atmospheric sulfur: Global implications for the sulfur budget, J. Geophys. Res.-Atmos., 114, 13, doi:10.1029/2008jd010486, 2009.

Barrie, L. A., Yi, Y., Leaitch, W. R., Lohmann, U., Kasibhatla, P., Roelofs, G. J., Wilson, J., McGovern, F., Benkovitz, C., Melieres, M. A., Law, K., Prospero, J., Kritz, M., Bergmann, D., Bridgeman, C., Chin, M., Christensen, J., Easter, R., Feichter, J., Land, C., Jeuken, A., Kjellstrom, E., Koch, D., and Rasch, P.: A comparison of large-scale atmospheric sulphate aerosol models (COSAM): overview and highlights, Tellus B, 53, 615-645, doi:10.1034/j.1600-0889.2001.530507.x, 2001.
Bei, N., Li, G., and Molina, L. T.: Uncertainties in SOA simulations due to meteorological uncertainties in Mexico City during MILAGRO-2006 field campaign, Atmos. Chem. Phys., 12, 11295-11308, doi:10.5194/acp-12-11295-2012, 2012.

Cao, J., Tie, X., Dabberdt, W. F., Jie, T., Zhao, Z., An, Z., and Shen, Z.: On the potential high acid deposition in northeastern China, J. Geophys. Res.-Atmos., 118, 4834-4846, doi:10.1002/jgrd.50381, 2013.

Chen, F. and Dudhia, J.: Coupling an advanced land surfacehydrology model with the Penn State-NCAR MM5 modeling system. Part I: Model implementation and sensitivity, Mon. Weather Rev., 129, 569-585, doi:10.1175/15200493(2001)129<0569:caalsh>2.0.co;2, 2001.

Chou, M.-D. and Suarez, M. J.: A solar radiation parameterization for atmospheric studies, NASA Tech. Rep. NASA/TM-199910460, 15, 38 pp., 1999.

Chou, M.-D. and Suarez, M. J.: A thermal infrared radiation parameterization for atmospheric studies, NASA/TM-2001-104606, 19, 55 pp., 2001.

Elser, M., Huang, R.-J., Wolf, R., Slowik, J. G., Wang, Q., Canonaco, F., Li, G., Bozzetti, C., Daellenbach, K. R., Huang, Y., Zhang, R., Li, Z., Cao, J., Baltensperger, U., El-Haddad, I., and Prévôt, A. S. H.: New insights into $\mathrm{PM}_{2.5}$ chemical composition and sources in two major cities in China during extreme haze events using aerosol mass spectrometry, Atmos. Chem. Phys., 16, 3207-3225, doi:10.5194/acp-16-3207-2016, 2016.

Feichter, J., Kjellstrom, E., Rodhe, H., Dentener, F., Lelieveld, J., and Roelofs, G. J.: Simulation of the tropospheric sulfur cycle in a global climate model, Atmos. Environ., 30, 1693-1707, doi:10.1016/1352-2310(95)00394-0, 1996.

Gerhardsson, L., Oskarsson, A., and Skerfving, S.: Acid precipitation effects on trace-elements and human health, Sci. Total Environ., 153, 237-245, doi:10.1016/0048-9697(94)90203-8, 1994.

Grell, G. A., Peckham, S. E., Schmitz, R., McKeen, S. A., Frost, G., Skamarock, W. C., and Eder, B.: Fully coupled "online" chemistry within the WRF model, Atmos. Environ., 39, 6957-6975, 2005.

Guenther, A., Karl, T., Harley, P., Wiedinmyer, C., Palmer, P. I., and Geron, C.: Estimates of global terrestrial isoprene emissions using MEGAN (Model of Emissions of Gases and Aerosols from Nature), Atmos. Chem. Phys., 6, 3181-3210, doi:10.5194/acp-63181-2006, 2006.

Guo, S., Hu, M., Zamora, M. L., Peng, J. F., Shang, D. J., Zheng, J., Du, Z. F., Wu, Z., Shao, M., Zeng, L. M., Molina, M. J., and Zhang, R. Y.: Elucidating severe urban haze formation in China, P. Natl. Acad. Sci. USA, 111, 17373-17378, doi:10.1073/pnas.1419604111, 2014.

Harris, E., Sinha, B., van Pinxteren, D., Tilgner, A., Fomba, K. W., Schneider, J., Roth, A., Gnauk, T., Fahlbusch, B., and Mertes, S.: Enhanced role of transition metal ion catalysis during in-cloud oxidation of $\mathrm{SO}_{2}$, Science, 340, 727-730, doi:10.1126/science.1230911, 2013.

He, H., Wang, Y. S., Ma, Q. X., Ma, J. Z., Chu, B. W., Ji, D. S., Tang, G. Q., Liu, C., Zhang, H. X., and Hao, J. M.: Mineral dust and $\mathrm{NO}_{x}$ promote the conversion of $\mathrm{SO}_{2}$ to sulfate in heavy pollution days, Scientific Report, 4, 5, doi:10.1038/srep04172, 2014.

Hong, S.-Y. and Lim, J.-O. J.: The WRF Single-Moment 6-Class Microphysics Scheme (WSM6), Asia-Pac. J. Atmos. Sci., 42, 129-151, 2006. 
Horowitz, L. W., Walters, S., Mauzerall, D. L., Emmons, L. K., Rasch, P. J., Granier, C., Tie, X. X., Lamarque, J. F., Schultz, M. G., Tyndall, G. S., Orlando, J. J., and Brasseur, G. P.: A global simulation of tropospheric ozone and related tracers: Description and evaluation of MOZART, version 2, J. Geophys. Res.-Atmos., 108, 29, doi:10.1029/2002jd002853, 2003.

Jacob, D. J. and Hoffmann, M. R.: A dynamic model for the production of $\mathrm{H}^{+}, \mathrm{NO}_{3}^{-}$, and $\mathrm{SO}_{4}^{2-}$ in urban fog, J. Geophys. Res.-Oc. Atm., 88, 6611-6621, doi:10.1029/JC088iC11p06611, 1983.

Jacob, D. J., Waldman, J. M., Munger, J. W., and Hoffmann, M. R.: A field investigation of physical and chemical mechanisms affecting pollutant concentrations in fog droplets, Tellus B, 36, 272-285, 1984.

Jacob, D. J., Gottlieb, E. W., and Prather, M. J.: Chemistry of a polluted cloudy boundary-layer, J. Geophys. Res.-Atmos., 94, 12975-13002, 10.1029/JD094iD10p12975, 1989.

Janjić, Z. I.: Nonsingular Implementation of the Mellor-Yamada Level 2.5 Scheme in the NCEP Meso Model, Ncep Office Note, 436, 2002.

Kasibhatla, P., Chameides, W. L., and StJohn, J.: A threedimensional global model investigation of seasonal variations in the atmospheric burden of anthropogenic sulfate aerosols, J. Geophys. Res.-Atmos., 102, 3737-3759, doi:10.1029/96jd03084, 1997.

Kawamoto, K., Hayasaka, T., Uno, I., and Ohara, T.: A correlative study on the relationship between modeled anthropogenic aerosol concentration and satellite-observed cloud properties over east Asia, J. Geophys. Res.-Atmos., 111, 7, doi:10.1029/2005jd006919, 2006.

Laskin, A., Gaspar, D. J., Wang, W. H., Hunt, S. W., Cowin, J. P., Colson, S. D., and Finlayson-Pitts, B. J.: Reactions at interfaces as a source of sulfate formation in sea-salt particles, Science, 301, 340-344, doi:10.1126/science.1085374, 2003.

Li, G., Zhang, R., Fan, J., and Tie, X.: Impacts of black carbon aerosol on photolysis and ozone, J. Geophys. Res.-Atmos., 110, D23206, doi:10.1029/2005JD005898, 2005.

Li, G., Lei, W., Zavala, M., Volkamer, R., Dusanter, S., Stevens, P., and Molina, L. T.: Impacts of HONO sources on the photochemistry in Mexico City during the MCMA-2006/MILAGO Campaign, Atmos. Chem. Phys., 10, 6551-6567, doi:10.5194/acp-106551-2010, 2010.

Li, G., Bei, N., Tie, X., and Molina, L. T.: Aerosol effects on the photochemistry in Mexico City during MCMA2006/MILAGRO campaign, Atmos. Chem. Phys., 11, 51695182, doi:10.5194/acp-11-5169-2011, 2011a.

Li, G., Zavala, M., Lei, W., Tsimpidi, A. P., Karydis, V. A., Pandis, S. N., Canagaratna, M. R., and Molina, L. T.: Simulations of organic aerosol concentrations in Mexico City using the WRFCHEM model during the MCMA-2006/MILAGRO campaign, Atmos. Chem. Phys., 11, 3789-3809, doi:10.5194/acp-11-37892011, 2011b.

Li, G., Lei, W., Bei, N., and Molina, L. T.: Contribution of garbage burning to chloride and $\mathrm{PM}_{2.5}$ in Mexico City, Atmos. Chem. Phys., 12, 8751-8761, doi:10.5194/acp-12-8751-2012, 2012.

Li, M., Zhang, Q., Kurokawa, J.-I., Woo, J.-H., He, K., Lu, Z., Ohara, T., Song, Y., Streets, D. G., Carmichael, G. R., Cheng, Y., Hong, C., Huo, H., Jiang, X., Kang, S., Liu, F., Su, H., and Zheng, B.: MIX: a mosaic Asian anthropogenic emission inventory under the international collaboration framework of the MICS-Asia and HTAP, Atmos. Chem. Phys., 17, 935-963, doi:10.5194/acp17-935-2017, 2017.

Mauldin III, R. L., Berndt, T., Sipila, M., Paasonen, P., Petaja, T., Kim, S., Kurten, T., Stratmann, F., Kerminen, V. M., and Kulmala, M.: A new atmospherically relevant oxidant of sulphur dioxide, Nature, 488, 193-196, doi:10.1038/nature11278, 2012.

Ministry of Environmental Protection, China (China MEP): Air Quality Observation Real-time Release Platform of MEP Data Center, available at: http://106.37.208.233:20035/, 2013a.

Ministry of Environmental Protection, China (China MEP): Online Monitoring and Analysis Platform of China Air Quality, available at: http://www.aqistudy.cn/, 2013b.

Nakajima, T., Higurashi, A., Kawamoto, K., and Penner, J. E.: A possible correlation between satellite-derived cloud and aerosol microphysical parameters, Geophys. Res. Lett., 28, 1171-1174, doi:10.1029/2000gl012186, 2001.

Nenes, A., Pandis, S. N., and Pilinis, C.: ISORROPIA: A new thermodynamic equilibrium model for multiphase multicomponent inorganic aerosols, Aquat. Geochem., 4, 123-152, doi:10.1023/a:1009604003981, 1998.

Pandis, S. N. and Seinfeld, J. H.: Mathematical modeling of acid deposition due to radiation fog, J. Geophys. Res., 94, 1291112923, 1989.

Pandis, S. N., Seinfeld, J. H., and Pilinis, C.: Heterogeneous sulfate production in an urban fog, Atmos. Environ. A-Gen., 26, 2509 2522, doi:10.1016/0960-1686(92)90103-r, 1992.

Schindler, D. W.: Effects of acid-rain on fresh-water ecosystems, Science, 239, 149-157, doi:10.1126/science.239.4836.149, 1988.

Seinfeld, J. H. and Pandis, S. N.: Atmospheric Chemistry and Physics: From Air Pollution to Climate Change, 2nd Edn., John Wiley \& Sons Inc., New York, 2006.

Sun, Y., Wang, Z., Fu, P., Jiang, Q., Yang, T., Li, J., and Ge, X.: The impact of relative humidity on aerosol composition and evolution processes during wintertime in Beijing, China, Atmos. Environ., 77, 927-934, 2013.

Tian, S. L., Pan, Y. P., and Wang, Y. S.: Size-resolved source apportionment of particulate matter in urban Beijing during haze and non-haze episodes, Atmos. Chem. Phys., 16, 1-19, doi:10.5194/acp-16-1-2016, 2016.

Wang, G., Zhang, R., Gomez, M. E., Yang, L., Levy, Z. M., Hu, M., Lin, Y., Peng, J., Guo, S., and Meng, J.: Persistent sulfate formation from London Fog to Chinese haze, P. Natl. Acad. Sci. USA, 113, 13630, doi:10.1073/pnas.1616540113, 2016.

Wang, X. F., Wang, W. X., Yang, L. X., Gao, X. M., Nie, W., Yu, Y. C., Xu, P., Zhou, Y., and Wang, Z.: The secondary formation of inorganic aerosols in the droplet mode through heterogeneous aqueous reactions under haze conditions, Atmospheric Environ., 63, 68-76, doi:10.1016/j.atmosenv.2012.09.029, 2012.

Wang, Y. X., Zhang, Q. Q., Jiang, J. K., Zhou, W., Wang, B. Y., He, K. B., Duan, F. K., Zhang, Q., Philip, S., and Xie, Y. Y.: Enhanced sulfate formation during China's severe winter haze episode in January 2013 missing from current models, J. Geophys. Res. Atmos., 119, 16, doi:10.1002/2013jd021426, 2014.

Wesely, M. L.: Parameterization of surface resistances to gaseous dry deposition in regional-scale numerical models, Atmos. Environ., 23, 1293-1304, doi:10.1016/0004-6981(89)90153-4, 1989.

Worsnop, D. R., Zahniser, M. S., Kolb, C. E., Gardner, J. A., Watson, L. R., Vandoren, J. M., Jayne, J. T., and Davidovits, P.: 
Temperature-dependence of mass accommodation of $\mathrm{SO}_{2}$ and $\mathrm{H}_{2} \mathrm{O}_{2}$ on aqueous surfaces, J. Phys. Chem., 93, 1159-1172, doi:10.1021/j100340a027, 1989.

Xie, Y. N., Ding, A. J., Nie, W., Mao, H. T., Qi, X. M., Huang, X., Xu, Z., Kerminen, V. M., Petaja, T., Chi, X. G., Virkkula, A., Boy, M., Xue, L. K., Guo, J., Sun, J. N., Yang, X. Q., Kulmala, M., and Fu, C. B.: Enhanced sulfate formation by nitrogen dioxide: Implications from in situ observations at the SORPES station, J. Geophys. Res.-Atmos., 120, 12679-12694, doi:10.1002/2015jd023607, 2015.

Xue, J., Yuan, Z., Griffith, S. M., Yu, X., Lau, A. K. H., and Yu, J. Z.: Sulfate Formation Enhanced by a Cocktail of High $\mathrm{NO}_{x}$, $\mathrm{SO}_{2}$, Particulate Matter, and Droplet $\mathrm{pH}$ during Haze-Fog Events in Megacities in China: An Observation-Based Modeling Investigation, Environmental Sci. Technol., 50, 7325-7334, 2016.

Zhang, Q., Streets, D. G., Carmichael, G. R., He, K. B., Huo, H., Kannari, A., Klimont, Z., Park, I. S., Reddy, S., Fu, J. S., Chen, D., Duan, L., Lei, Y., Wang, L. T., and Yao, Z. L.: Asian emissions in 2006 for the NASA INTEX-B mission, Atmos. Chem. Phys., 9, 5131-5153, doi:10.5194/acp-9-5131-2009, 2009.
Zhang, R., Leu, M. T., and Keyser, L. F.: Hydrolysis of $\mathrm{N}_{2} \mathrm{O}_{5}$ and $\mathrm{ClONO}_{2}$ on the $\mathrm{H}_{2} \mathrm{SO}_{4} / \mathrm{HNO}_{3} / \mathrm{H}_{2} \mathrm{O}$ ternary solutions under stratospheric conditions, Geophys. Res. Lett., 22, 1493-1496, 1995.

Zhang, R. Y., Wang, G. H., Guo, S., Zarnora, M. L., Ying, Q., Lin, Y., Wang, W. G., Hu, M., and Wang, Y.: Formation of Urban Fine Particulate Matter, Chem. Rev., 115, 3803-3855, doi:10.1021/acs.chemrev.5b00067, 2015.

Zhao, J., Levitt, N. P., Zhang, R., and Chen, J.: Heterogeneous reactions of methylglyoxal in acidic media: implications for secondary organic aerosol formation, Environ. Sci. Technol., 40, 7682-7687, 2006.

Zheng, G. J., Duan, F. K., Su, H., Ma, Y. L., Cheng, Y., Zheng, B., Zhang, Q., Huang, T., Kimoto, T., Chang, D., Pöschl, U., Cheng, Y. F., and He, K. B.: Exploring the severe winter haze in Beijing: the impact of synoptic weather, regional transport and heterogeneous reactions, Atmos. Chem. Phys., 15, 2969-2983, doi:10.5194/acp-15-2969-2015, 2015. 